\title{
ARTICLE Robo4 contributes to the turnover of Peyer's patch B cells
}

Ruth Fair-Mäkelä ${ }^{1}$, Milas Ugur ${ }^{2}$, Imtiaz Iftakhar-E-Khuda ${ }^{1}$, Laura Kähäri ${ }^{1}$, Anu Kukkonen-Macchi ${ }^{1}$, Heini-Maria Brenyah ${ }^{1}$, Kati Elima ${ }^{1}$, Masayuki Miyasaka', Oliver Pabst ${ }^{2}$ and Sirpa Jalkanen ${ }^{1}$

All leukocytes can get entrance into the draining lymph nodes via the afferent lymphatics but only lymphoid cells can leave the nodes. The molecular mechanisms behind this phenomenon have remained unknown. We employed genome wide microarray analyses of the subcapsular sinus and lymphatic sinus (LS) endothelial cells and found Robo4 to be selectively expressed on LS lymphatics. Further analyses showed high Robo4 expression in lymphatic vessels of Peyer's patches, which only have efferent lymphatic vessels. In functional assays, Robo4-deficient animals showed accumulation of naïve $B$ cells $\left(C D 19^{+} / C D 62 L^{\text {hi }} / C D 44^{l o}\right)$ in Peyer's patches, whereas no difference was seen within other lymphocyte subtypes. Short-term lymphocyte homing via high endothelial venules to peripheral and mesenteric lymph nodes and Peyer's patches was also slightly impaired in Robo4 knockout animals. These results show for the first time, selective expression of Robo4 in the efferent arm of the lymphatics and its role in controlling the turnover of a subset of B lymphocytes from Peyer's patches.

Mucosal Immunology (2020) 13:245-256; https://doi.org/10.1038/s41385-019-0230-9

\section{INTRODUCTION}

Lymphocytes recirculate continuously between the blood and lymphatic organs. ${ }^{1}$ Most lymphocytes enter the lymphoid organs via the high endothelial venules. Molecular mechanisms and different phases in lymphocyte-blood vessel endothelial cell interactions during the lymphocyte extravasation have been extensively studied during the last 30 years and are currently well known. ${ }^{2-5}$ In contrast, cell trafficking via the lymphatics is much less characterized although it is a central functional part of our immune system and a route for cancer cells to metastasize. Certain lymphocytes, dendritic cells, and other leukocytes together with antigens enter the lymph nodes via afferent lymphatic vessels, which drain to the subcapsular sinus (SS) of the lymph nodes. In physiological conditions only lymphoid cells, however, can exit the nodes via the efferent lymphatic sinuses (LS). ${ }^{6-8}$ The exit routes for lymphoid cells go via chains of lymph nodes. ${ }^{9}$ For example, cells leaving the popliteal lymph nodes go next to sacral and further to iliac lymph nodes and cells leaving the Peyer's patches (PP) go to the mesenteric lymph nodes (MLN). ${ }^{10,11}$ Although discriminative trafficking between the afferent and efferent arms is a well-known phenomenon, its molecular basis has remained largely unknown.

We have characterized the afferent and efferent lymphatic endothelial cells (LEC) of the lymph nodes and found a multitude of molecular differences between these different arms of the lymphatic system. ${ }^{12}$ One of the differently expressed molecules was magic roundabout, i.e. Robo4, a member of the Roundabout axon guidance family. ${ }^{12}$ The microarray data can be found at www.ncbi.nlm.nih.gov/geo (accession no. GSE68371). Robo4 was first characterized on blood endothelium, ${ }^{13}$ although it is also expressed on hematopoietic stem cells in the bone marrow. It determines their location in the bone marrow niches and regulates directional trafficking of the stem cells. ${ }^{14,15}$ On blood endothelium Robo4 contributes to endothelial cell integrity, as well as to permeability and inhibits pathologic angiogenesis by antagonizing the function of VEGF. ${ }^{16}$ Robo4 has been reported to interact with UNC5B and Slit2, although there has been some debate about the role of Slit2 as a ligand of Robo4. ${ }^{17-19}$ Slit2 was found to inhibit lipopolysaccharide-induced secretion of certain inflammatory mediators and monocyte adhesion to the endothelium in a Robo4-mediated fashion suggesting the importance of the Slit2-Robo4 pathway in regulating the state of the endothelium at sites of inflammation. ${ }^{20}$

The role of Robo4 on lymphatics is poorly known. To date, it has only been studied by using LEC in vitro. Slit2-inhibited VEGF-Cinduced proliferation, migration, and tube formation of LEC in vitro and the effect was Robo4 dependent. ${ }^{21}$ In this present study, we found selective expression of Robo4 in the efferent arm of the lymphatics and explored its possible role in lymphocyte turnover in the peripheral and mucosal nodes. The results indicate a new function for Robo4: it controls turnover of a $B$ cell subpopulation in PP.

\section{RESULTS}

Robo4 is preferentially expressed on the efferent arm of the lymphatics

Genome wide microarray analyses were performed using RNA from isolated LECs of murine SS and LS using the laser capture microdissection method and cell sorting with flow cytometry. ${ }^{12}$ The purpose was to identify differentially expressed genes between the afferent and efferent arms of the lymphatic vasculature in the lymph nodes. In combined analyses, Robo4 had a 13.1-fold higher expression in LS than in SS (www.ncbi.nlm.nih.gov/geo (accession

\footnotetext{
${ }^{1}$ MediCity Research Laboratory and Institute of Biomedicine, University of Turku, 20520 Turku, Finland and ${ }^{2}$ Institute of Molecular Medicine, RWTH Aachen University, 52074 Aachen, Germany

Correspondence: Sirpa Jalkanen (sirpa.jalkanen@utu.fi)

These authors contributed equally: Milas Ugur, Imtiaz Iftakhar-E-Khuda
}

Received: 1 April 2019 Revised: 21 October 2019 Accepted: 4 November 2019

Published online: 26 November 2019 
no. GSE68371)). Expression of Robo4 on lymphatics as such was in agreement with the ImmGen data regarding Robo4 expression in blood and lymphatic vessel endothelial cells (http://www.immgen. org/databrowser/, Fig. 1a, b), and therefore, we wanted to analyze its role in the lymphatics more closely. It turned out that none of the tested antibodies (commercial and available) worked in immunohistochemical stainings in mouse, but did so in immunofluorescence stainings of cell suspensions followed by FACS analyses. To check whether Robo4 is present on the efferent lymphatics, we first stained lineage ${ }^{-}, \mathrm{CD}^{-} 5^{-} /$podopla$\mathrm{nin}^{+} / \mathrm{LYVE} 1^{+}$cells from peripheral and mesenteric lymph nodes (PLN and MLN pooled) (Fig. 1c). To analyze Robo4 expression in
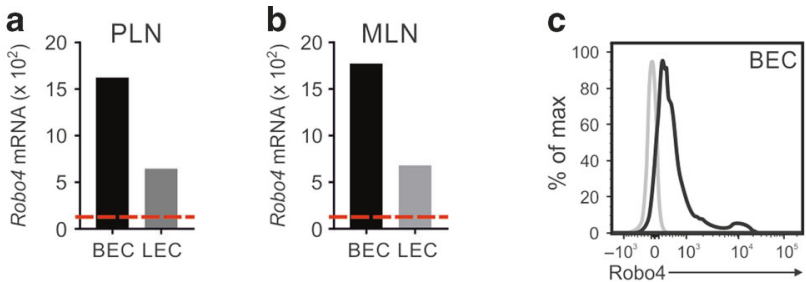

d

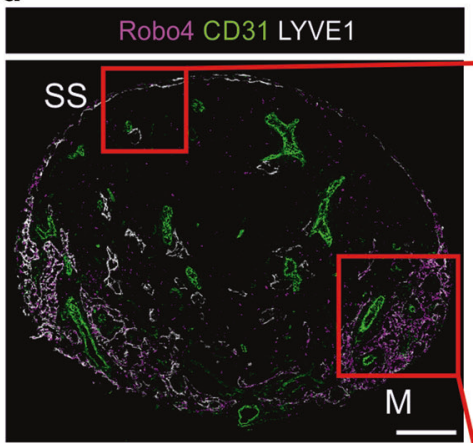

e

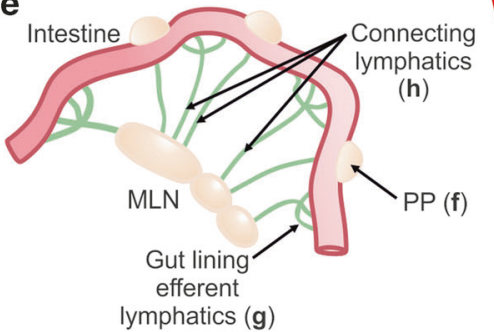

g
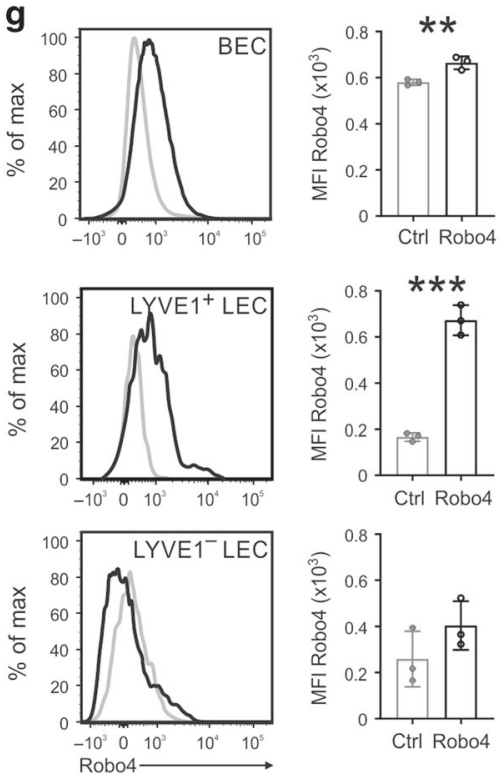
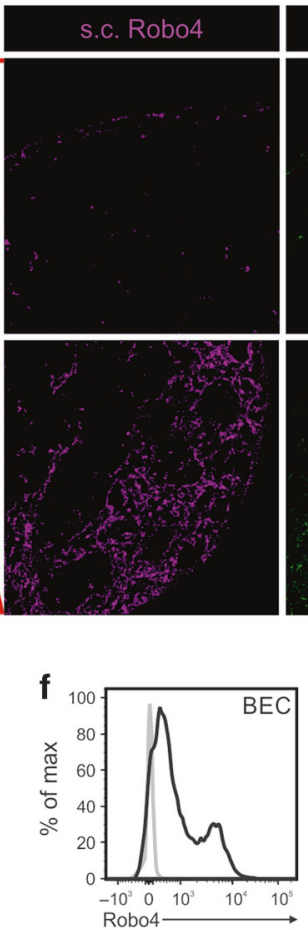

h
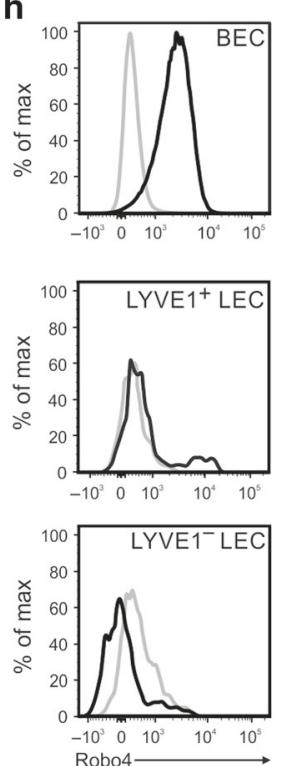

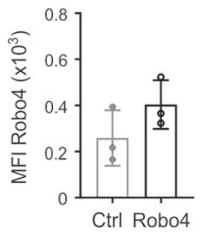

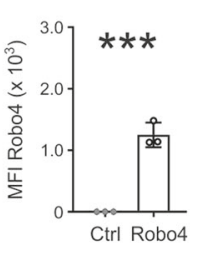
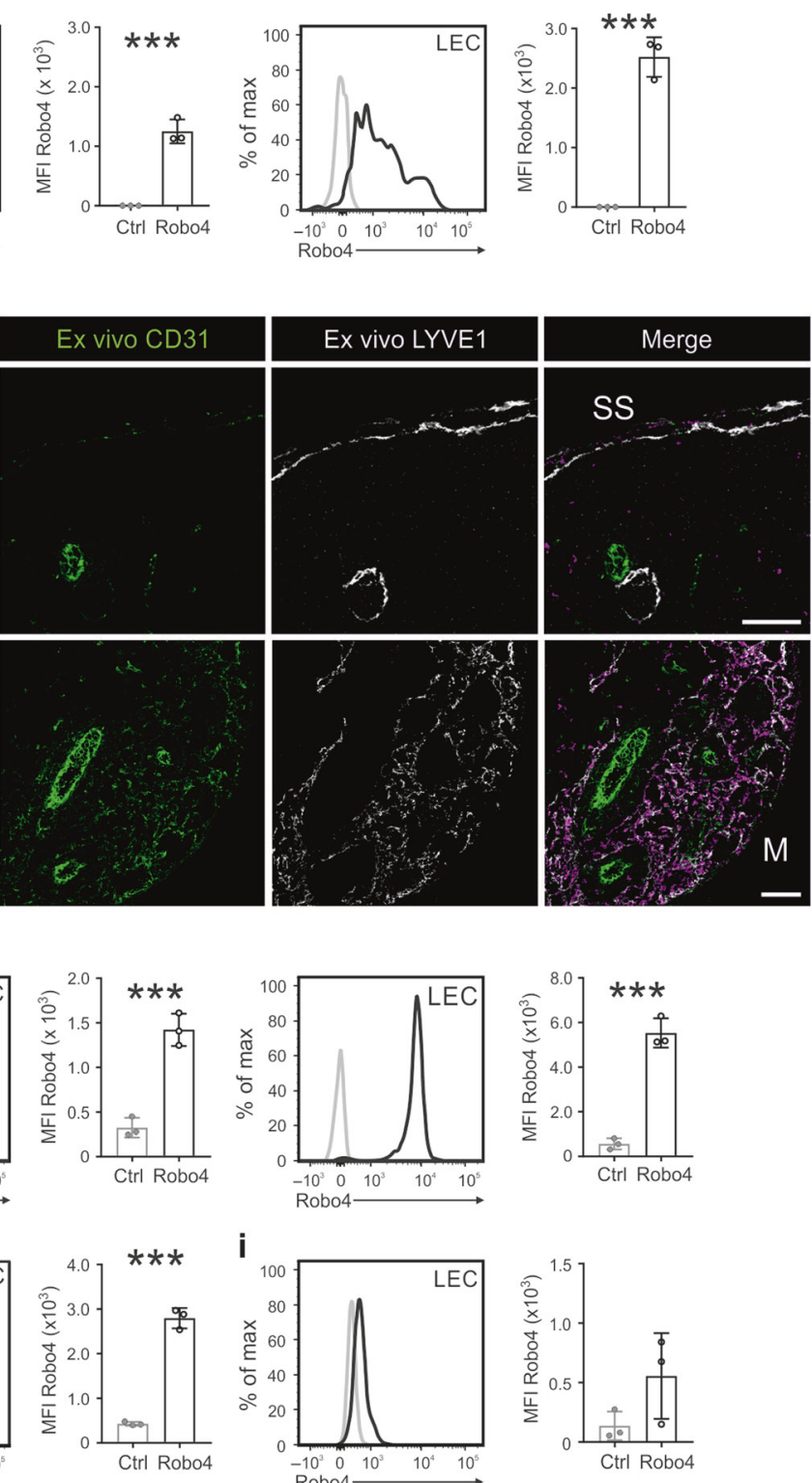
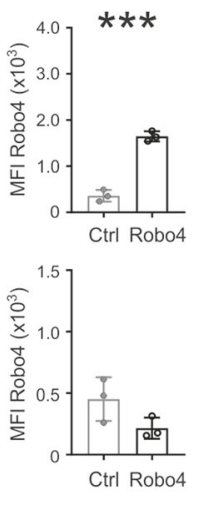
Fig. 1 Robo4 is expressed on lymphatic and blood vessel endothelium. a, b Expression of Robo4 mRNA in peripheral lymph nodes (PLN, a) or mesenteric lymph node (MLN, b) of wild-type C57BL/6J mice. mRNA expression was detected from lymphatic endothelial cells (CD45 ${ }^{-}$, CD31 ${ }^{+}$, Podoplanin $\left.{ }^{+}, \mathrm{LEC}\right)$ and blood endothelial cells $\left(\mathrm{CD} 45^{-}, \mathrm{CD} 31^{+}\right.$, Podoplanin $\left.{ }^{-}, \mathrm{BEC}\right)$. Data are from the Immunological genome project, mean values above 120 (dashed red line) are regarded as positive with 95\% confidence. c Robo4 protein expression is detected in WT BEC and LEC. The cells were isolated and pooled from PLN and MLN. d Immunostaining of popliteal lymph node after subcutaneous (s.c.) administration of Robo4-A647 antibody and ex vivo staining of CD31 and LYVE1 to detect the BEC and LEC cell populations. Scale bars $200,50 \mu m$ zoom-ins, $n=$ 3. e A schematic drawing of gut lymph nodes and lymphatics showing the Peyer's patches (PP), the efferent lymphatics leading from the lamina propria and PP to the MLN, arrows point to the areas analyzed for Robo4 expression in $\mathbf{f}-\mathbf{h}$. Robo4 protein expression was analyzed with flow cytometry from BEC, LEC, LYVE1 ${ }^{+}$LEC and LYVE1 ${ }^{-}$LEC isolated from PP f, the gut-lining region $\mathbf{g}$, and connecting lymphatics between the gut and MLN h. i Robo4 expression in skin LEC. Black histograms, Robo4; gray histograms, isotype-specific control. Flow cytometry in $\mathbf{c}$ and $\mathbf{f}-\mathbf{i} n=3$. Data are presented as mean \pm S.D. ${ }^{* * *} P<0.001,{ }^{* *} P<0.01$ (two-tailed Student's $t$-test). M medulla, SS subcapsular sinus.

immunohistochemical stainings, we produced a monoclonal antimurine Robo4 antibody by taking advantage of Robo4 KO animals (Fig. S1a-e). To detect Robo4 in the lymph node we administered the Robo4 antibody subcutaneously (s.c.) into the footpads of C57BL/6 mice to harness the draining lymphatics to deliver the antibody to its targets in the draining lymph node. Non-specific binding of the antibody to macrophage Fc receptors was blocked using Fc receptor-blocking antibodies and mouse immunoglobulins administered before and with the anti-Robo4 antibody. ${ }^{22}$ Robo4 expression was detected mainly in the efferent lymphatics in the medullary region (Figs. 1d and S2a, b). Very faint Robo4 expression was also visible in the LYVE1 ${ }^{-}$LECs of the SS roof, whereas the LYVE1 $^{+}$floor seemed to be negative for Robo4 (Fig. 1d). According to the observations by Kähäri et al. ${ }^{22}$ s.c. injected antibodies do not reach the luminal side of blood vessels, which may well explain why we were not able to detect vascular Robo4 after S.c. injection of the antibody (Fig. 1d). Expression of Robo4 was particularly high and homogenous in LECs isolated from PP Fig. 1e, f). This observation is consistent with the lack of afferent lymphatics in PP. Thus, LECs within PP might mostly resemble efferent lymphatics and consistently express Robo4. Moreover, we tested Robo4 expression on lymphatics leading from the gut to the MLN (Fig. 1e). Expression of Robo4 on LYVE1 ${ }^{+}$LEC was higher in the close vicinity to the gut than on lymphatic vessels further away leading to the MLN, which become afferent vessels for MLN by definition (Fig. 1g, h).

Heterogeneous expression of Robo4 was seen in LECs of PLN and MLN. Only a subpopulation was as highly positive as in PP while the rest of the LEC were practically negative (Fig. 1c). Similarly, we stained skin lymphatics, which all are afferent lymphatics by definition. Very little staining was seen in these cells (Fig. 1i).

Robo4 on human efferent lymphatics supports lymphocyte binding

Next, we tested whether the expression of human Robo4 resembles that of mouse. Also in human lymph nodes collected from the head and neck region, Robo4 was expressed on a subset of LS endothelial cells and it was absent from the lymphatic endothelium in SS (Fig. 2a, b). We used the appendix as an organized human mucosal lymphoid tissue in the expression analyses. A subpopulation of Prox-1-positive lymphatics in human appendix was Robo4 positive (Fig. 2c). To explore a possible role of human Robo4 on the LS endothelium, we performed ex vivo frozen section-binding assays. In this assay, lymphocytes bind specifically to the lymphatic endothelium in the SS and LS (and to high endothelial venules, HEV, which are easy to discriminate from the lymphatic endothelium by their plump morphology). ${ }^{12,23}$ AntiRobo4 antibody significantly inhibited lymphocyte binding to the lymphatic endothelium in the LS but not in the SS (Fig. 2d, Fig. S3a-d) suggesting that Robo4 on the lymphatic endothelium of LS directly interacts with lymphocytes.

The major lymphocyte pools and lymphatic architecture is normal in Robo4 knockout mice

Next, we took advantage of Robo4 KO mice and studied their lymphocyte pools and lymphatic and blood vasculature in PP.
Special emphasis was put on the PP, because of the abundant Robo4 expression on their lymphatics. The major lymphocyte pools (B220, CD4, and CD8) did not differ statistically significantly and they showed comparable anatomic localization in PP (Fig. 3a-d). Numbers of CD4 and CD8 cells were lower in PLN of $\mathrm{KO}$ mice than in their controls but such a difference was not observed in MLN (Fig. S4a-d).

Despite the suggested role of Robo4 in angiogenesis and lymphangiogenesis, the lymphatic and blood vasculature analyzed by using anti-LYVE1, anti-MAdCAM-1, and anti-CD31 antibodies was normal based on the area the vessels covered and their microscopical appearance. Data regarding PP are shown in Fig. 3e-h.

Robo4 contributes to lymphocyte entrance to PP

As Robo4 is abundantly present on blood endothelium, we first checked its possible contribution to lymphocyte entrance into the lymph nodes via HEV. We adoptively transferred congenic CD45.1 $1^{+}$lymphocytes into Robo4 KO and WT animals and analyzed them from PP, PLN, MLN, and peripheral blood 2 and $18 \mathrm{~h}$ after the i.v. injections. There was a slight decrease at the 2-h time point in the homing of all CD45. $1^{+}$and CD45. $1^{+}$CD4 ${ }^{+}$cells to the PP of Robo4 KO mice in comparison to their WT controls (Fig. 4a). In contrast, no differences at the 18-h time point were seen (Fig. 4b, the gating strategy is shown in Fig. S5a-d) suggesting a statistically significant contribution for Robo4 in lymphocyte homing via HEV to PP at early time points. A concomitant increase in the number of transferred cells in peripheral blood of $\mathrm{KO}$ mice was observed (Fig. 4c). We also checked the homing of CD45.1 $1^{+}$lymphocytes to PLN and MLN and observed a quantitatively minor, although statistically significant decrease in the homing of different lymphocyte subpopulations to these organs in Robo4 $\mathrm{KO}$ mice in comparison to their WT controls (Fig. S5e-h). There were no significant anatomical differences in the distribution of transferred cells between the KO and WT mice in PP (Fig. 4d, e) or PLN and MLN (Fig. S6a-d).

Robo4 is involved in B cell turnover in PP

To study the turnover of endogenous lymphocytes FITC was injected into PPs. In this model, FITC will label the lymphocytes and the kinetics of the turnover can simply be analyzed by measuring the number of different FITC-positive lymphocyte subsets retaining in PPs after $24 \mathrm{~h}$. These studies showed that more $\mathrm{CD} 19^{+}$and especially $\mathrm{CD} 62^{\mathrm{hi}} \mathrm{CD} 44^{\mathrm{lo}} \mathrm{B}$ cells were left in the PPs of Robo4 KO than in those of WT mice suggesting a Robo4dependent mechanism regulating B cell turnover in PP (Fig. 5a, b). There was no difference in the number of $T$ cell subtypes suggesting a clearly specific contribution of Robo4 towards the B cell turnover. There was also a trend towards an impaired exit of lymphocytes from popliteal lymph nodes to iliac lymph nodes after lymphocyte transfer to footpads (Fig. S7a, b). We then performed GPCR analyses of PP B cells to discover possible changes in selected molecules known to be involved in lymphocyte exit and maybe indirectly affected by lack of Robo4 on lymphatics or imprinting during the development as 
a
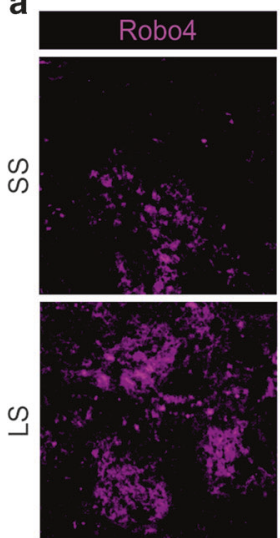
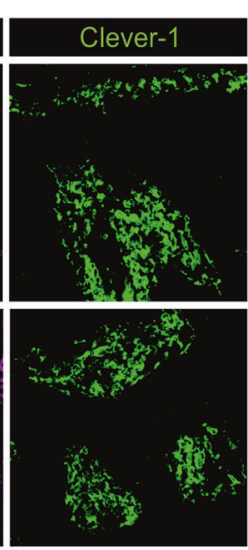

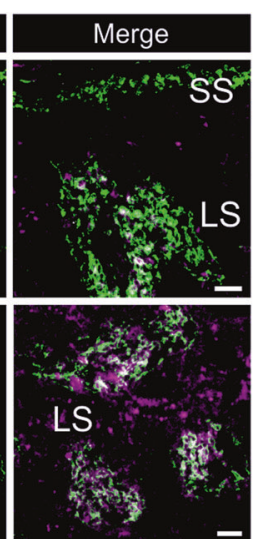

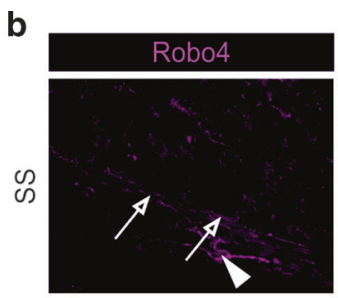

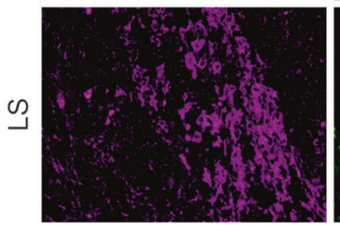

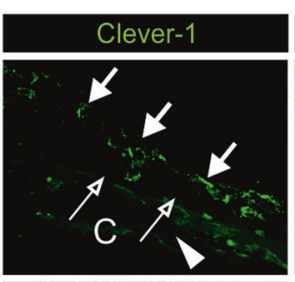

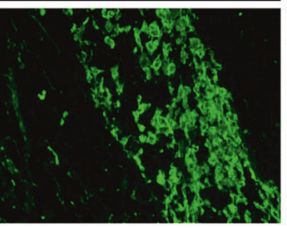

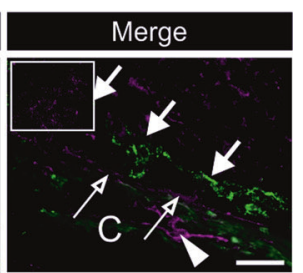

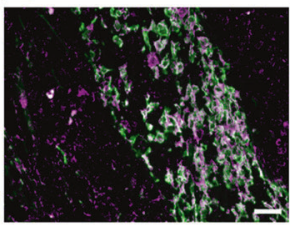

c

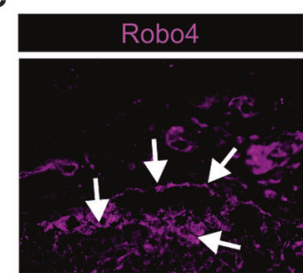

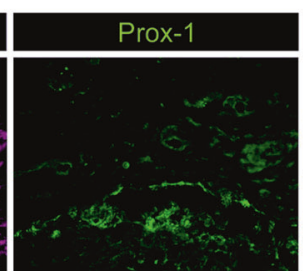
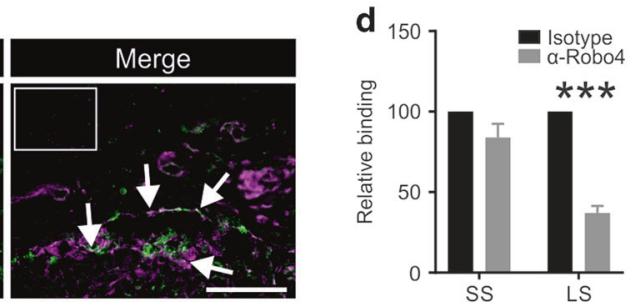

Fig. 2 Robo4 is expressed in human efferent lymphatics where it mediates binding of lymphocytes to the lymphatic sinus. a, $\mathbf{b}$ Low power images of immunostaining of Robo 4 and Clever-1 (a lymphatic endothelial marker) in human lymph nodes a. In the close-up images b the arrowhead indicates Robo4 ${ }^{+}$Clever- $1^{-}$blood vessel in the capsule, open arrows point to Robo4 ${ }^{-}$Clever- $1^{-1 / 0}$ roof of SS and closed arrows indicate the Robo4 ${ }^{-}$Clever- $1^{+}$floor of SS; Robo4 ${ }^{+}$Clever- $1^{+}$lymphatics are only present in LS. c Immunostaining of Robo4 and Prox 1 in the human appendix. Arrows indicate Robo4 ${ }^{+}$Prox $1^{+}$lymphatic staining. Negative control stainings for Robo 4 are shown in the boxed areas. Representatives of three lymph nodes and three appendix samples from different individuals (scale bars $50 \mu \mathrm{m}$ ). d Adhesion of peripheral blood lymphocytes to lymph node frozen sections $(n=12)$ analyzed by ex vivo adhesion assays of three different individuals. The sections were treated with anti-Robo4 or an isotype control antibody and adhered lymphocytes were enumerated manually from the subcapsular and lymphatic sinuses. Data is shown as the adhesion of lymphocytes to anti-Robo4-treated samples in relation to their isotype controls. The control values were set as 100 by definition. Data are presented as mean \pm S.D. ${ }^{* * *} P<0.001$ (two-tailed Student's $t$-test). C capsule, SS subcapsular sinus, LS lymphatic sinus.

hematopoietic stem cells express Robo4. PP B cells had significantly less S1P receptor 1 signal most likely contributing to the impaired turnover of B cells from the PP (Fig. S8a-c). We next checked how well $\mathrm{CD} 19^{+} \mathrm{CD} 62 \mathrm{~L}^{\text {hi }} \mathrm{CD} 44^{\mathrm{lo}} \mathrm{B}$ cells enter PP in adoptive transfer assays. The results clearly showed that the entrance of this B cell subpopulation was normal in Robo4 $\mathrm{KO}$ mice (Fig. 5c). In the immunohistological analyses, $\mathrm{CD} 19^{+} \mathrm{CD}_{22} \mathrm{~L}^{\text {hi }} \mathrm{CD} 44^{\text {lo }} \mathrm{B}$ cells are mainly located in the mantle zone of germinal centers in PP (Fig. 5d) and can be classified as naïve based on their IgD positivity (Fig. 5 e). When analyzing the $\mathrm{CD}_{22} \mathrm{~L}^{\text {hi }} \mathrm{CD} 44^{\text {lo }}$ population of total $\mathrm{CD} 19^{+} \mathrm{B}$ cells in the FITCinjection experiments (Fig. 5a, b), no differences were found between KO and WT animals (Fig. 5f) suggesting a slower turnover for that population in the KO animals. We also employed thorough endogenous B cell subtype analyses of PP and found that the mean values of naïve and germinal center B cells in PP were higher in the KO mice. This, however, showed only a trend in statistical analyses (Fig. 5g-n). Similarly, the numbers of B cell progenitors in bone marrows were comparable between Robo4 $\mathrm{KO}$ and their controls (Fig. S9a-e) as were the numbers of B cell subpopulations in MLN expect for regulatory $B$ cells, the number of which were higher in KO mice (Fig. S9f-i).

Robo4 KO have slightly increased apoptosis in PP

As the KO mice retain CD19-positive B cells in PP in excess without any difference in their entrance two possibilities remain; the PPs have more apoptosis regulating the increasing cell amount over time or they enlarge over time in Robo4 KO mice. We tested these two possibilities. To study the rate of apoptosis we analyzed Robo4 KO and WT PP lymphocytes by staining them for Annexin V that binds to externally exposed phosphatidylserine on the cell membrane. We analyzed the early apoptotic Annexin $\mathrm{V}^{+}$ population in total $\mathrm{CD}_{4} 5^{+}$hematopoietic cells, $\mathrm{B} 220^{+} \mathrm{B}$ cells, and $\mathrm{CD}^{+} \mathrm{T}$ cells (Fig. $6 \mathrm{a}-\mathrm{c}$ ) and discovered that Robo4 $\mathrm{KO}$ mice have a slight increase in the total cell number of $C D 45^{+}$Annexin $\mathrm{V}^{+}$early apoptotic cells. The late stage of apoptosis was measured with the TUNEL assay detecting cells with fragmented DNA from Robo4 KO and WT PP-frozen sections (Fig. 6d, e). In these stainings, the TUNEL assay revealed a comparable number and localization of the apoptotic cells in the whole PP and the follicle regions in Robo4 KO mice and their WT controls. Our data suggests that Robo4 KO mice have a slightly activated rate of apoptosis among $\mathrm{B} 220^{+} \mathrm{B}$ cells that may keep the size of PP under control.

Imbalance in MLN homeostasis leads to increased tissue size While Robo4 KO PP were not enlarged when their tissue weight was normalized to the weight of the animal, MLN of Robo4 KO mice had a greater mass when compared to their WT controls at ages of 12 weeks or more (Fig. 7a, b). To study what would cause the increased growth of MLN in these mice, we examined the size of different $B$ cell populations (Fig. 7c, d). The percentage of $\mathrm{CD} 19^{+} \mathrm{CD} 2 \mathrm{~L}^{-} \mathrm{CD} 44^{+}$population was slightly increased in Robo4 KO MLN (Fig. 7d). CD19 ${ }^{+} \mathrm{CD} 62 \mathrm{~L}^{\text {hi }} \mathrm{CD} 44^{\text {lo }} \mathrm{B}$ cells localized in the mantle zone of B cell follicles similar to PP (Fig. 7e). However, an increase in one $B$ cell population does not explain the clear increase in tissue weight. Therefore, we examined the total percentage and number of $\mathrm{CD} 19^{+} \mathrm{B}$ cells, which was not altered in Robo4 KO MLN (Fig. 7f). There was no increase in the total CD45 ${ }^{+}$ hematopoietic cells in Robo4 KO MLN either (Fig. 7g). To study the 
a

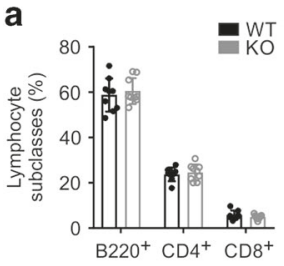

C

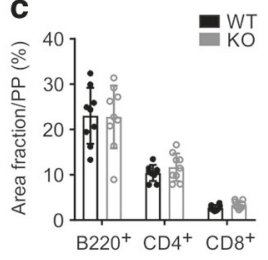

b
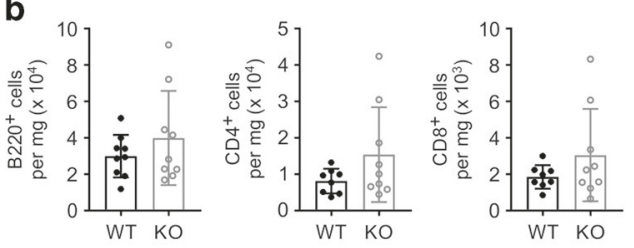

e
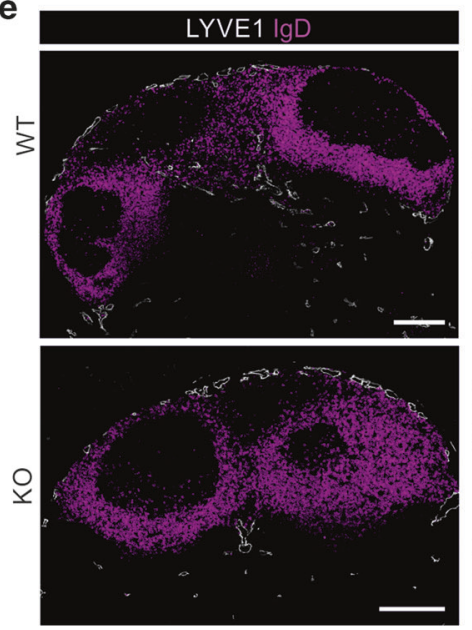

h
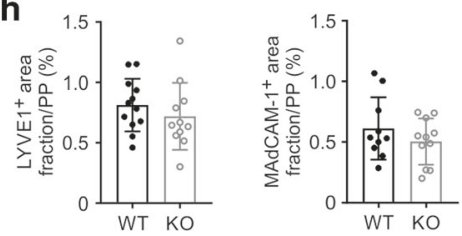
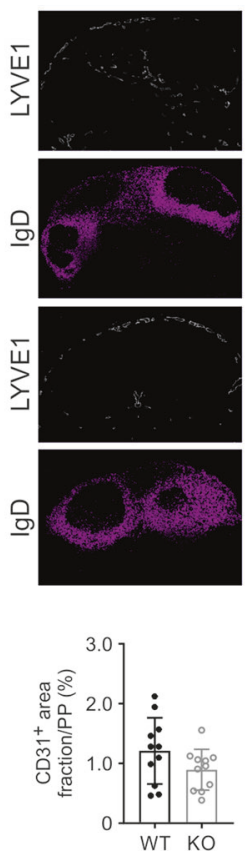

d
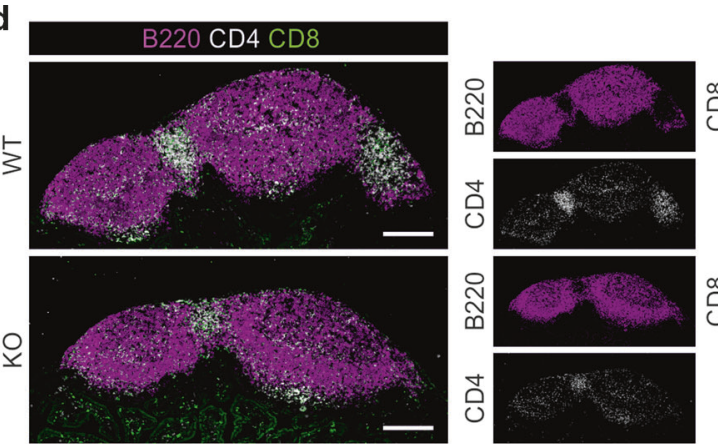
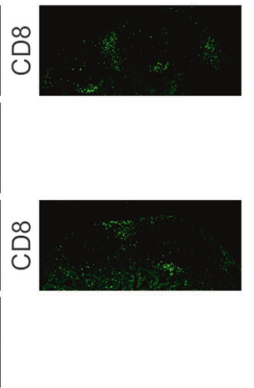

f

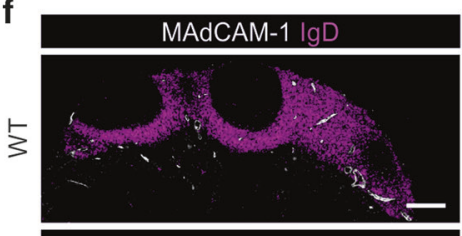

MAdCAM-1
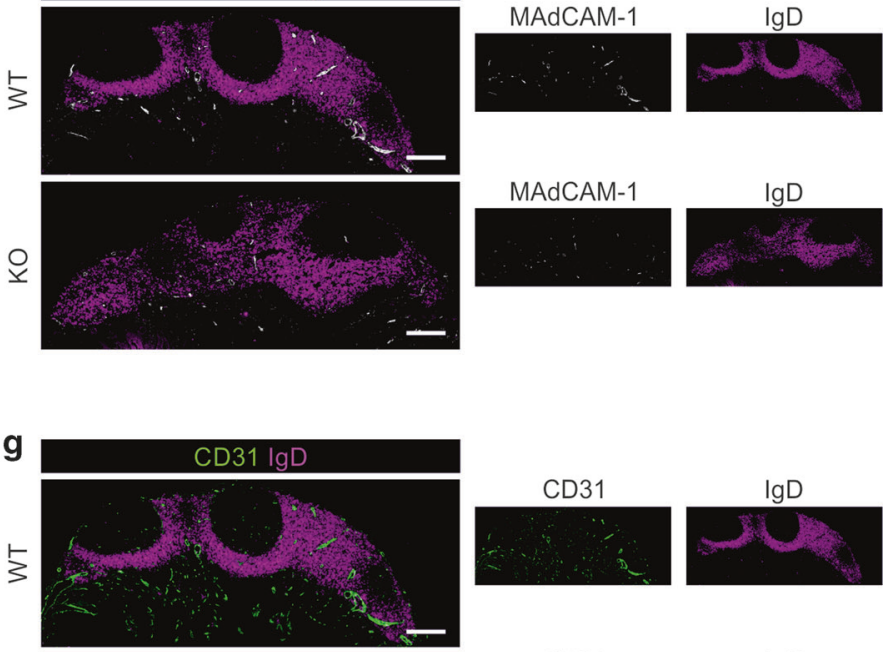

CD31
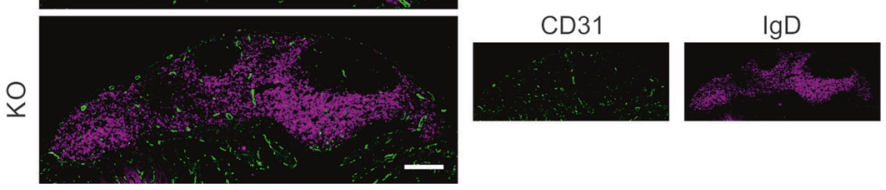

Fig. 3 Robo4 KO mice have a normal number and distribution of lymphocytes and endothelial cells in PP. Frequency a and number $\mathbf{b}$ of B cells $\left(\mathrm{B}_{2} 2 \mathrm{O}^{+}\right), \mathrm{CD}^{+}$, and $\mathrm{CD} 8^{+}$T cells in the total lymphocyte pool in Robo4 KO and WT PP assessed by flow cytometry. Data are pooled from two independent experiments with 8-9 WT and 9 Robo4 KO mice. c-h Immunostainings and quantifications of Robo4 KO and WT PP showing distribution of lymphocyte subpopulations c, d, LYVE1 ${ }^{+}$lymphatics $\mathbf{e}, \mathbf{h}$, MAdCAM-1 ${ }^{+}$HEV detected with a secondary antibody after i.v. injections of Meca367 antibody f, h or CD31 ${ }^{+}$blood vessels $\mathbf{g}, \mathbf{h}$. Images were quantified from 3 to 4 WT and 3 Robo4 KO mice from 1 to 2 individual PP per mouse and 1-3 sections per PP, scale bars $200 \mu \mathrm{m}$. Data are presented as mean \pm S.D. Each dot represents an individual mouse $\mathbf{a}, \mathbf{b}$ or an analyzed sample $\mathbf{c}-\mathbf{h}$.

apoptotic rate, we stained MLN lymphocytes with Annexin $\mathrm{V}$ and quantified the early apoptotic cells as well as the dead cells in Robo4 KO MLN. Although the rate of early apoptotic cells was comparable in Robo4 KO and WT MLN, a clear increase in the dead cell population in $\mathrm{CD}_{4} 5^{+}$cells, B220 ${ }^{+} \mathrm{B}$ cells, and $\mathrm{CD} 3^{+} \mathrm{T}$ cells was found (Fig. 7h, i). This was accompanied by increased collagen I deposits (Fig. 7j).

\section{DISCUSSION}

The function of Robo4 as a regulator of angiogenesis, endothelial cell migration, and blood vascular integrity has been demonstrated. ${ }^{16,18,24}$ In contrast, very little is known regarding its expression and function in the lymphatics. In this work, we found Robo4 to be preferentially expressed on the efferent arm of the lymphatic system. The finding was further confirmed by the presence of Robo4 in the lymphatics of PP, which are by definition efferent in their nature as PP do not have any afferent lymphatics. However, when approaching the MLN the PP draining lymphatics lose Robo4 expression-a finding that is compatible with the fact that these same vessels become afferent for the MLN. The expression pattern of Robo4 in these different arms of the lymphatics opposes the expression of macrophage scavenger receptor, which is discriminatively expressed on afferent lymphatics while being absent on the efferent ones. ${ }^{12}$

Although the diverse roles of Robo4 on blood endothelium presented above have been demonstrated, its possible role in leukocyte trafficking via HEV in organized lymphoid tissues has not been addressed. About $80 \%$ of the lymphocytes are thought to enter the lymph nodes via HEV while $20 \%$ enter via the afferent lymphatics. ${ }^{25}$ To be able to address the role of Robo4 in the trafficking dynamics of recirculating lymphocytes, we first studied whether Robo4 on HEVs contributes to lymphocyte entrance into the nodes. The results of these assays suggest that Robo4 does 

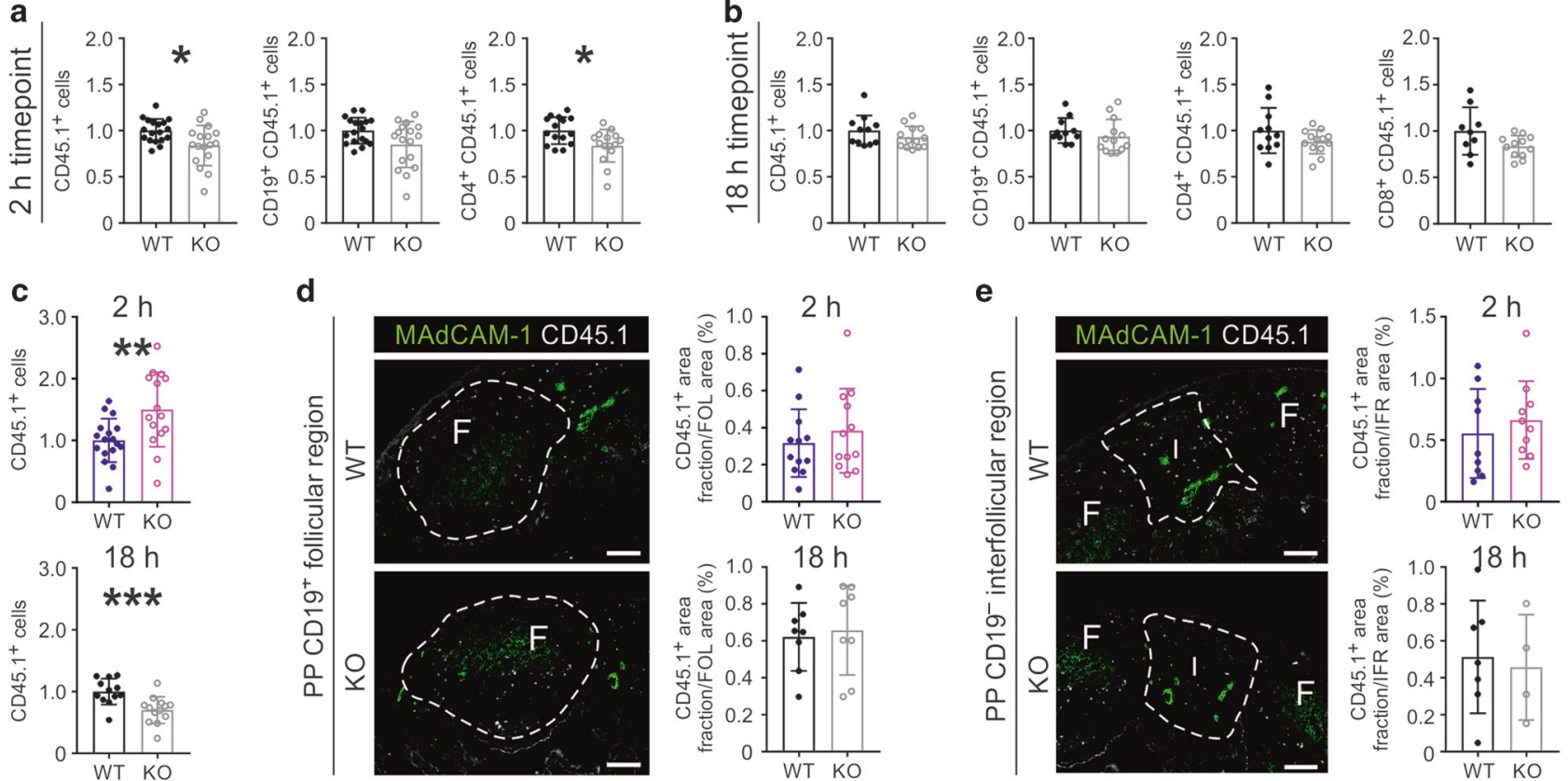

Fig. 4 Vascular Robo4 regulates short-term lymphocyte migration to PP $\mathbf{a}$, b Relative number of adoptively transferred CD45.1 $1^{+}$total lymphocytes, CD19+ CD45. ${ }^{+} \mathrm{B}$ cells, CD4 ${ }^{+} \mathrm{CD} 45.1^{+}$, and CD8 ${ }^{+} \mathrm{CD} 45.1^{+} \mathrm{T}$ cells recovered in PP with flow cytometry $2 \mathrm{~h}$ a or $18 \mathrm{~h}$ b after intravenous injections of donor cells into Robo4 KO and WT recipients. c Relative amount of adoptively transferred CD45.1 $1^{+}$lymphocytes recovered from peripheral blood with flow cytometry $2 \mathrm{~h}$ (top) or $18 \mathrm{~h}$ (bottom) after intravenous injections of donor cells into Robo $4 \mathrm{KO}$ and WT recipients. In a-c data are pooled from three independent 2-h and two independent 18-h adoptive transfer assays with 15-17 Robo4 KO and 15-18 WT (2-h) or 12-13 Robo4 KO and 9-11 WT mice (18-h). The mean value of WT mice is defined as 1.0. d, e The distribution of adoptively transferred CD45.1 $1^{+}$cells was analyzed from PP-frozen sections and the percentage (\%) of CD45.1 $1^{+}$cells was quantified from $\mathrm{CD}_{19}{ }^{+} \mathrm{B}$ cell follicles $\mathbf{d}$ or CD19 ${ }^{-}$inter-follicular regions e at $2 \mathrm{~h}$ (top) or $18 \mathrm{~h}$ (bottom) after intravenous injections based on the signal area covered by CD45.1 $1^{+}$cells/total area analyzed. Image quantification was performed from 1 to 2 independent 2 and 18-h experiments analyzing 3-9 Robo4 KO and WT mice. Sections were analyzed from a total of 8-12 d or 4-10 e PP. Representative images are shown from the 18-h adoptive transfer experiment (scale bars $=100 \mu \mathrm{m})$. Data are presented as mean \pm S.D. ${ }^{*} P<0.05,{ }^{* *} P<0.01,{ }^{* * *} P<0.001($ Mann-Whitney U-test). Each dot represents an individual mouse a-c or an analyzed sample d, e. F follicle, I inter-follicular region.

have a minor contribution to the entrance of certain lymphocyte subpopulations via the blood vessels into the PLN, MLN, and PP, but the $B$ cell homing via HEV to PP is at the same level both in Robo4 KO and their WT controls. Therefore, it is unlikely that the entry via HEV would contribute to the impaired turnover of the $B$ cells by any means.

Originally, we performed genome wide screening of endothelial cells isolated from afferent and efferent lymphatics, because we were interested in finding molecules discriminatively expressed on the afferent and efferent arms of the lymphatic vasculature. $^{12}$ In addition, we were searching for potential candidates that would be responsible either for the leukocyte entry into the nodes or for selective lymphocyte access into the efferent lymphatics while leaving the nodes. Therefore, Robo4 seemed to be a good candidate in this respect. In functional assays, we utilized Robo4 $\mathrm{KO}$ mice and injected FITC locally into the PP. The results showed that a subset of endogenous $B$ cells accumulate and thus, may have difficulties in leaving PP while CD4 and CD8 cells leave normally. We also detected significantly lower levels of S1P receptor 1 in PP B cells in Robo4 KO mice than in those of their WT controls. How can Robo4 have an effect on this? One possibility is imprinting during early developmental phases as Robo4 is expressed by hematopoietic stem cells. Alternatively, lack of Robo4 in the lymphatics may indirectly affect the exit machinery of the lymphocytes.

Ex vivo-adhesion assays measuring lymphocyte binding to HEV in frozen sections were originally presented by Stamper and Woodruff. ${ }^{26}$ Since then, several modifications have been employed including measurements of leukocyte and tumor cell binding to different types of lymphatic vessels. ${ }^{23,27,28}$ Importantly this method has shown its usability for the molecular identification of several interaction partners both on leukocytes and vascular walls. ${ }^{29,30}$ Many of the molecules functionally characterized this way have been later used as targets in drug development. ${ }^{31-33}$ We also utilized this method to test, whether anti-Robo4 antibody is able to inhibit lymphocyte binding to lymphatics in human lymph nodes. The results of these assays unambiguously demonstrated that lymphocyte-lymphatic endothelial cell interaction in the LS but not in the SS is Robo4 dependent being in agreement with the expression pattern of Robo4.

In conclusion, we have for the first time demonstrated the discriminative expression of Robo4 in the efferent arm of the lymphatic vasculature and its role in regulating the composition of $B$ cell populations in PP. This may happen at least partially by adhesive interactions between $B$ cells and endothelial cells within LS. Robo4 differs from CXCR4, Clever-1, and sphingosine 1 phosphate, which contribute to lymphocyte egress from PP but are also involved in lymphocyte trafficking in the afferent arm of the lymphatics. ${ }^{34-36}$ This finding is expected to facilitate future studies regarding the possibilities to target Robo4 and thus, manipulate the immune response.

\section{MATERIALS AND METHODS}

Mice

C57BL/6 mice were purchased from Jackson Laboratory and Janvier labs. Robo4 KO mice, 129S6(B6)-Robo4 ${ }^{\text {tm1Lex }} /$ Mmucd (stock number 032543-UCD), and their wild-type controls from 
a

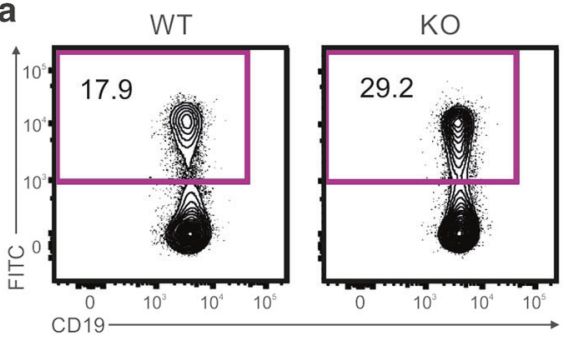

b

CD19+

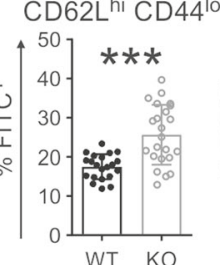

$\mathrm{CD} 4^{+}$ CD62L hi CD44

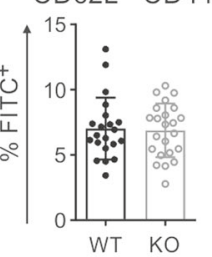

$\mathrm{CD}^{+}$

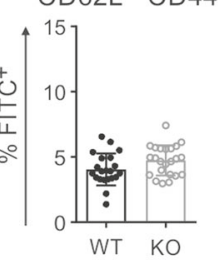

C

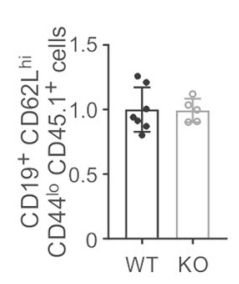

d
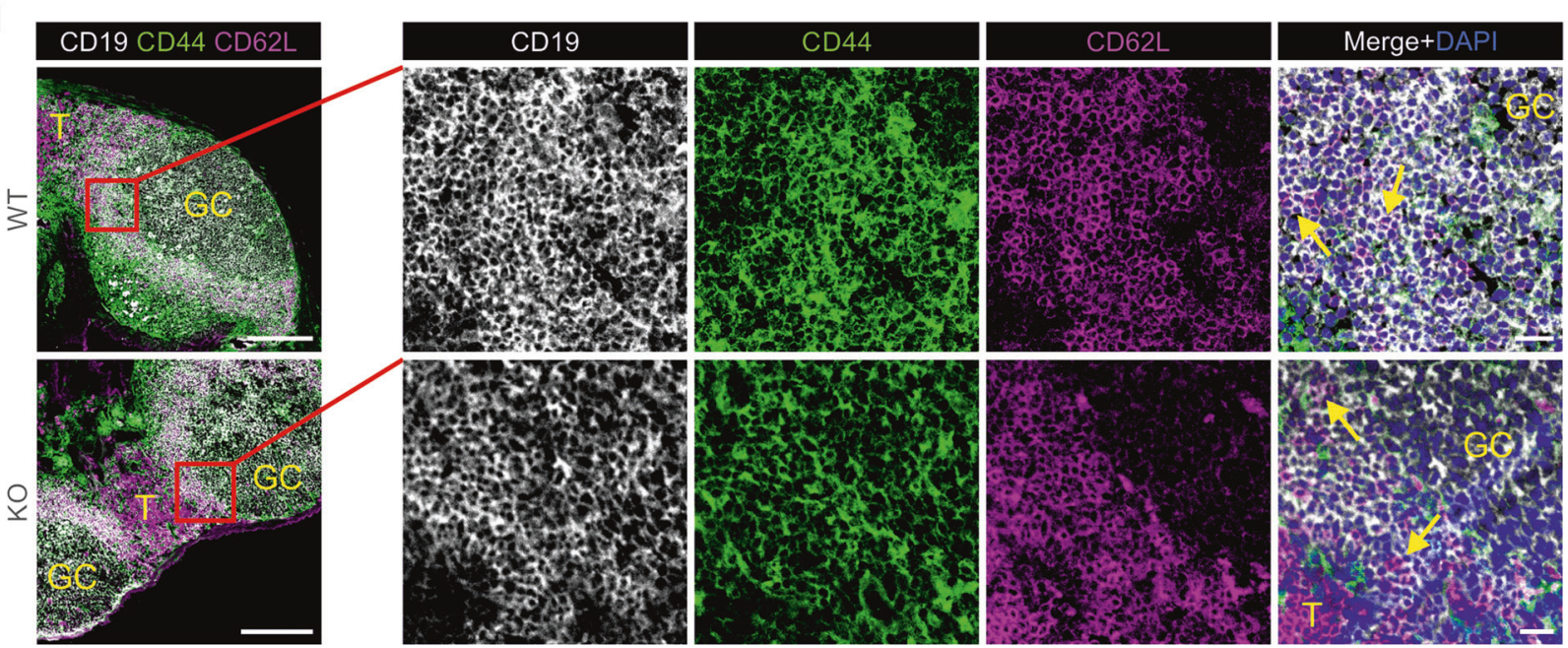

e

f
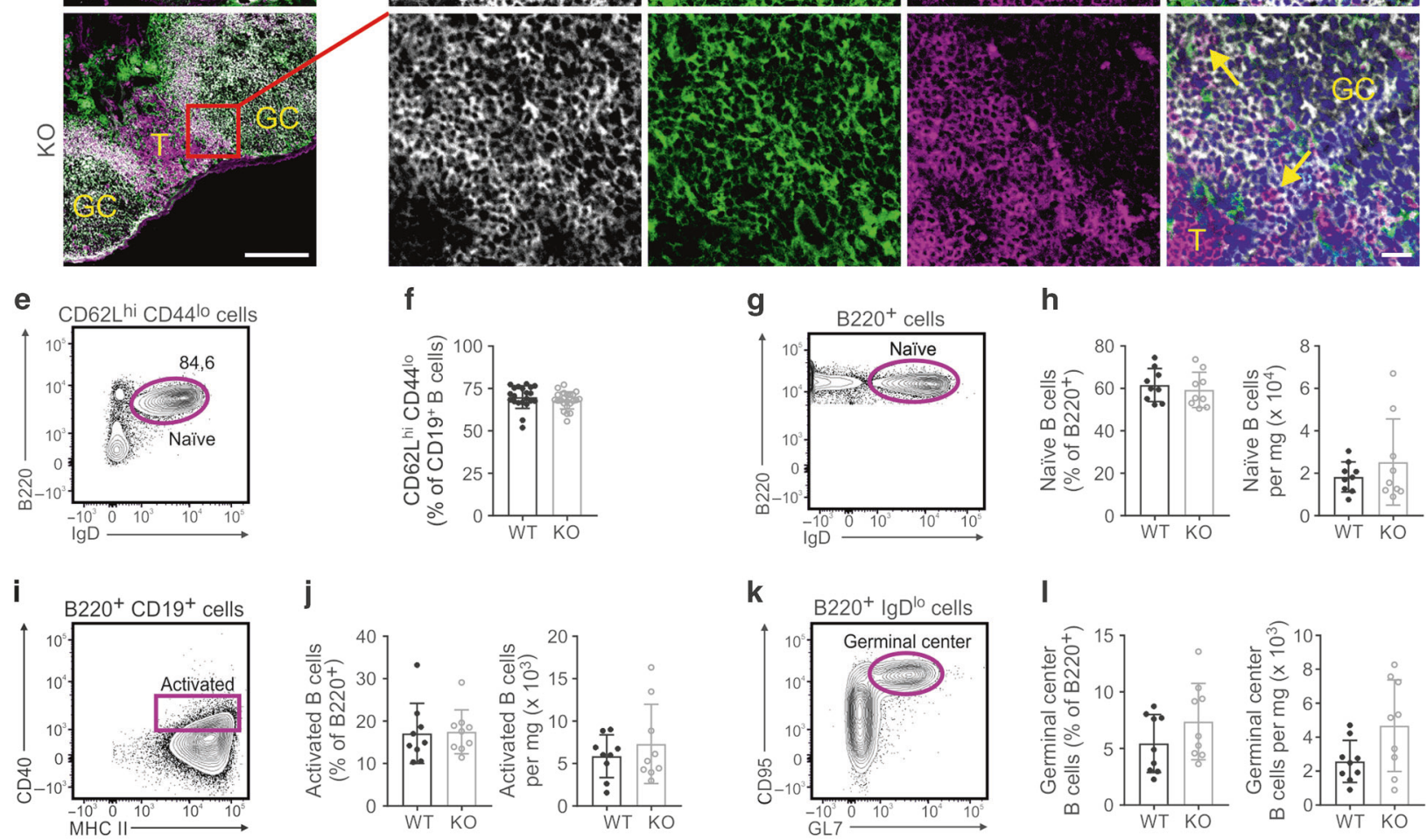

g

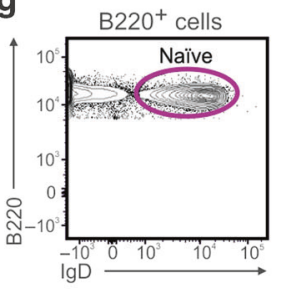

k

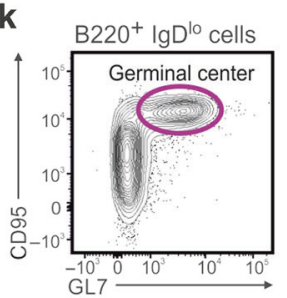

h
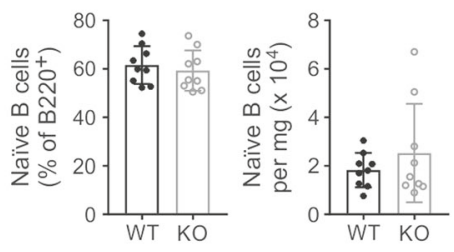

I
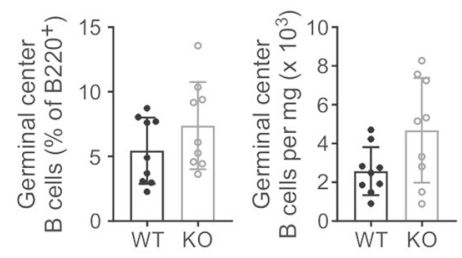

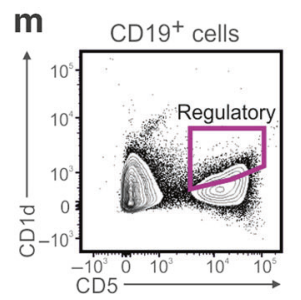

n

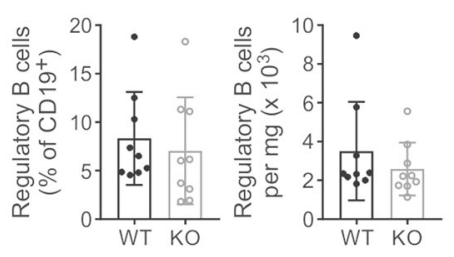

the same genetic background were purchased from Lexicon genetics Inc. Mice were bred as separate Robo4 KO and WT lines. Congenic CD45.1 $1^{+}$B6.SJL-Ptprc ${ }^{a}$ Pepc $^{b} /$ BoyJ mice were purchased from Jackson Laboratory (stock number 002014). Age and sex-matched controls were used for the study. Robo4 KO mice have originally been subjected to a broad phenotypic screen aiming at identifying defects in metabolism, function of the cardiovascular, neurological, or immunological systems, as

well as involvement in oncogenesis, but no notable phenotype alterations were found. ${ }^{37}$ All animal experiments were approved by the Ethical Committee for Animal Experimentation in Finland and Germany. Experiments were performed according to the rules and regulations of The Finnish Act on Animal Experimentation $(497 / 2013)$ in compliance with the 3R-principle with the appropriate animal licenses (5587/04.10.07/2014, 5762/04.10.07/ 2017 and 84-02.04.2014.A330). 
Fig. 5 Robo4 KO mice retain especially $\mathrm{CD} 19^{+} \mathrm{CD} 62 \mathrm{~L}^{\text {hi }} \mathrm{CD} 44^{\mathrm{lo}} \mathrm{B}$ cells in their PP. a Representative plots showing frequencies of FITC ${ }^{+} \mathrm{CD}_{22} \mathrm{~L}^{\text {hi }} \mathrm{CD} 44^{\mathrm{lo}}$ cells among CD19+ cells in FITC-injected PP $24 \mathrm{~h}$ post injections. b Frequency of FITC ${ }^{+} \mathrm{CD} 19^{+} \mathrm{CD} 62 \mathrm{~L}^{\mathrm{hi}} \mathrm{CD} 44^{\mathrm{lo}} \mathrm{B}$ cells (left), CD4 ${ }^{+} \mathrm{CD} 62 \mathrm{~L}^{\mathrm{hi}} \mathrm{CD} 44^{\mathrm{lo}} \mathrm{T}$ cells (middle) and CD8 ${ }^{+} \mathrm{CD} 62 \mathrm{~L}^{\text {hi }} \mathrm{CD} 44^{\mathrm{lo}} \mathrm{T}$ cells (right) recovered by flow cytometry from FITC-injected Robo4 KO and WT PP $24 \mathrm{~h}$ after FITC injections. Combined data are pooled from three individual experiments performed with six WT and six KO mice per group. c Relative number of adoptively transferred naïve CD19+ $\mathrm{CD} 62 \mathrm{~L}^{\text {hi }} \mathrm{CD} 44^{\text {lo }} \mathrm{CD} 45.1^{+} \mathrm{B}$ cells recovered from Robo4 KO and WT PP with flow cytometry $18 \mathrm{~h}$ after intravenous injections of CD45.1 ${ }^{+}$donor cells into Robo4 KO and WT recipients. Data are from seven WT and five KO mice. d Localization of $\mathrm{CD} 19^{+} \mathrm{CD} 62 \mathrm{~L}^{\mathrm{hi}} \mathrm{CD} 44^{\mathrm{lo}} \mathrm{B}$ cells. Arrows point to clusters of these cells (scale bars $200 \mu \mathrm{m}$ in main images, $20 \mu \mathrm{m}$ in zoomins), $n=3 \mathrm{WT}$ and $3 \mathrm{KO}$ mice. e Gating of the $\mathrm{CD} 19^{+} \mathrm{CD} 62^{\text {hi }} \mathrm{CD} 44^{\mathrm{lo}}$ population of $\mathrm{B}$ cells for the analysis of IgD positivity (naïve $\mathrm{B}$ cells). f Frequency (\%) of the CD62 $\mathrm{L}^{\text {hi}} \mathrm{CD} 44^{\mathrm{lo}}$ population of total $\mathrm{CD} 19^{+} \mathrm{B}$ cells in the experiments described in $\mathbf{a}$ and $\mathbf{b}$. g- $\mathbf{n}$ Analysis of endogenous B cell populations in Robo4 KO and WT PP. Gating strategy and quantification of naïve B cells $\left(\mathrm{B}_{2} 20^{+} \operatorname{lgD}{ }^{+} ; \mathbf{g}, \mathbf{h}\right)$, activated B cells (B220 ${ }^{+}$

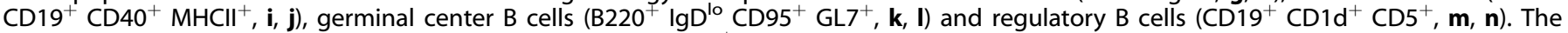
percentage (\%) of B cell subpopulations was normalized to $B 220^{+} B$ cells (left graph) and the number of B cell subpopulations is reported in relation to $\mathrm{mg}$ of tissue (right graph). Endogenous B cells were quantified from two independent experiments using 9 WT and $9 \mathrm{KO}$ mice. Each dot represents an individual PP $\mathbf{b}, \mathbf{f}$ or an individual mouse $(\mathbf{c}, \mathbf{h}, \mathbf{j}, \mathbf{I}, \mathbf{n})$. Data are presented as mean \pm SD. ${ }^{* * * P}<0.001$ (Mann-Whitney $U$-test). T T cell area, GC germinal center.

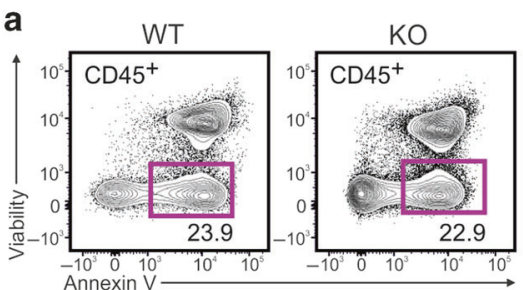

b
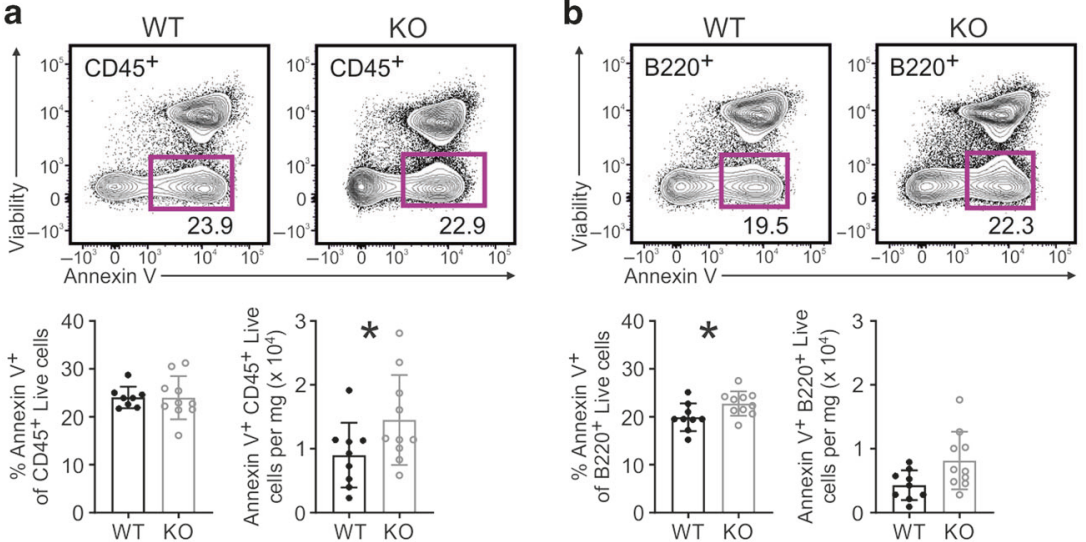

d

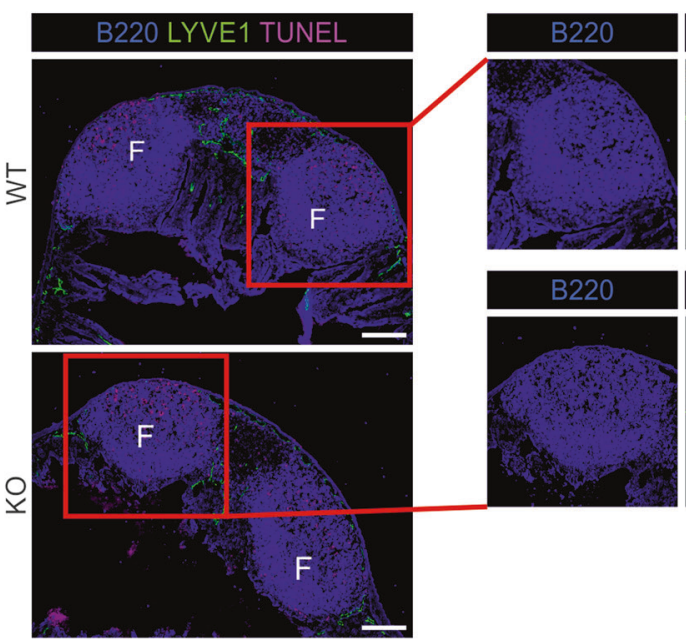

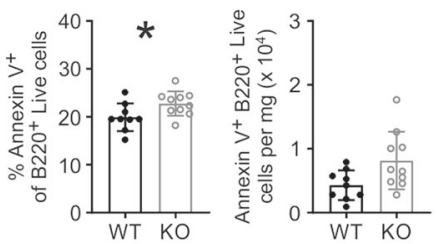

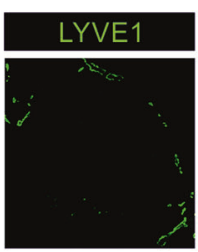

LYVE1

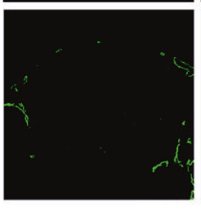

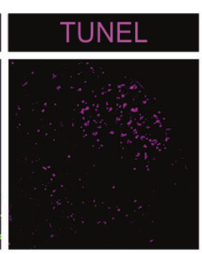
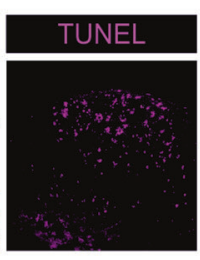

C
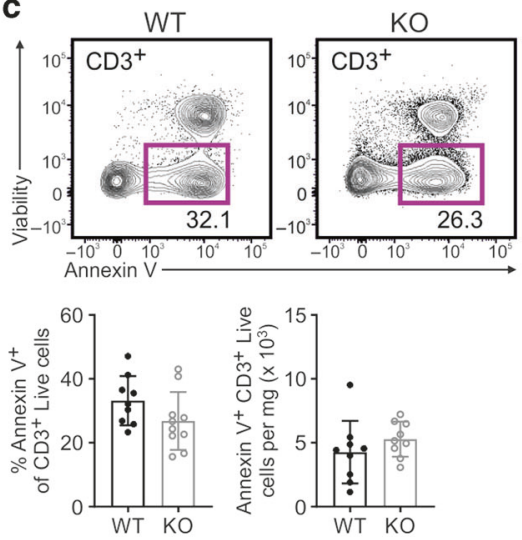

e

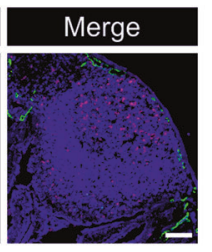

Merge

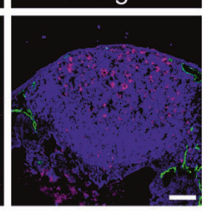

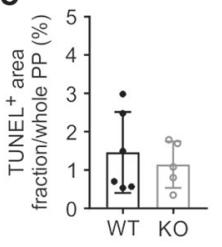

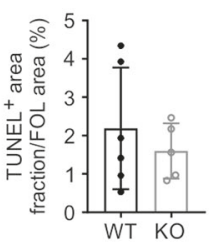

Fig. 6 Robo4 KO mice have slightly increased apoptosis in PP. a-c Early apoptotic cells in Robo4 KO and WT PP. Frequency (\%) and total cell numbers in relation to $\mathrm{mg}$ of tissue of early apoptotic Annexin ${ }^{+} \mathrm{CD} 45^{+}$cells $\mathbf{a}$, Annexin ${ }^{+} \mathrm{B}_{220^{+}} \mathrm{B}$ cells $\mathbf{b}$, and Annexin ${ }^{+} \mathrm{CD} 3^{+} \mathrm{T}_{\text {cells }}$ c analyzed from Robo4 KO and WT PP. Apoptotic cells were quantified from two independent experiments using 8-9 WT and 9-10 KO mice. d Representative images from Robo4 KO and WT PP showing end-phase apoptotic cells detected with TUNEL assay, B220 ${ }^{+}$B cells and LYVE1 ${ }^{+}$ lymphatics (scale bars $200 \mu \mathrm{m}$ in main images, $100 \mu \mathrm{m}$ in zoom-ins). e Quantification of the percentage (\%) of TUNEL ${ }^{+}$area in Robo4 KO and WT PP analyzed from the whole PP area (top) of follicle area (bottom). Quantification of TUNEL ${ }^{+}$signal was performed from six WT and five KO PP isolated from three WT and three KO mice. Data are presented as mean \pm S.D. ${ }^{*} P<0.05$ (Mann-Whitney $U$-test). F follicle.

Human material

Human lymph nodes and appendix samples were obtained from surplus tissues from surgical operations. Tissues were carefully examined macroscopically and microscopically before using tissues for experiments. Only tissues that were observed as normal were used for further experimentation. Mononuclear cells were isolated from healthy volunteers with the permission of the Ethical Committee of the Turku University Hospital.
Antibodies

The antibodies used in this work are listed in Supplementary Table 1.

\section{Flow cytometry}

When analyzing lymphocytes, single-cell suspensions were prepared by homogenizing PLN, MLN, and PP with custom-made metal cell strainers or nylon filters followed by additional filtering. LEC and 

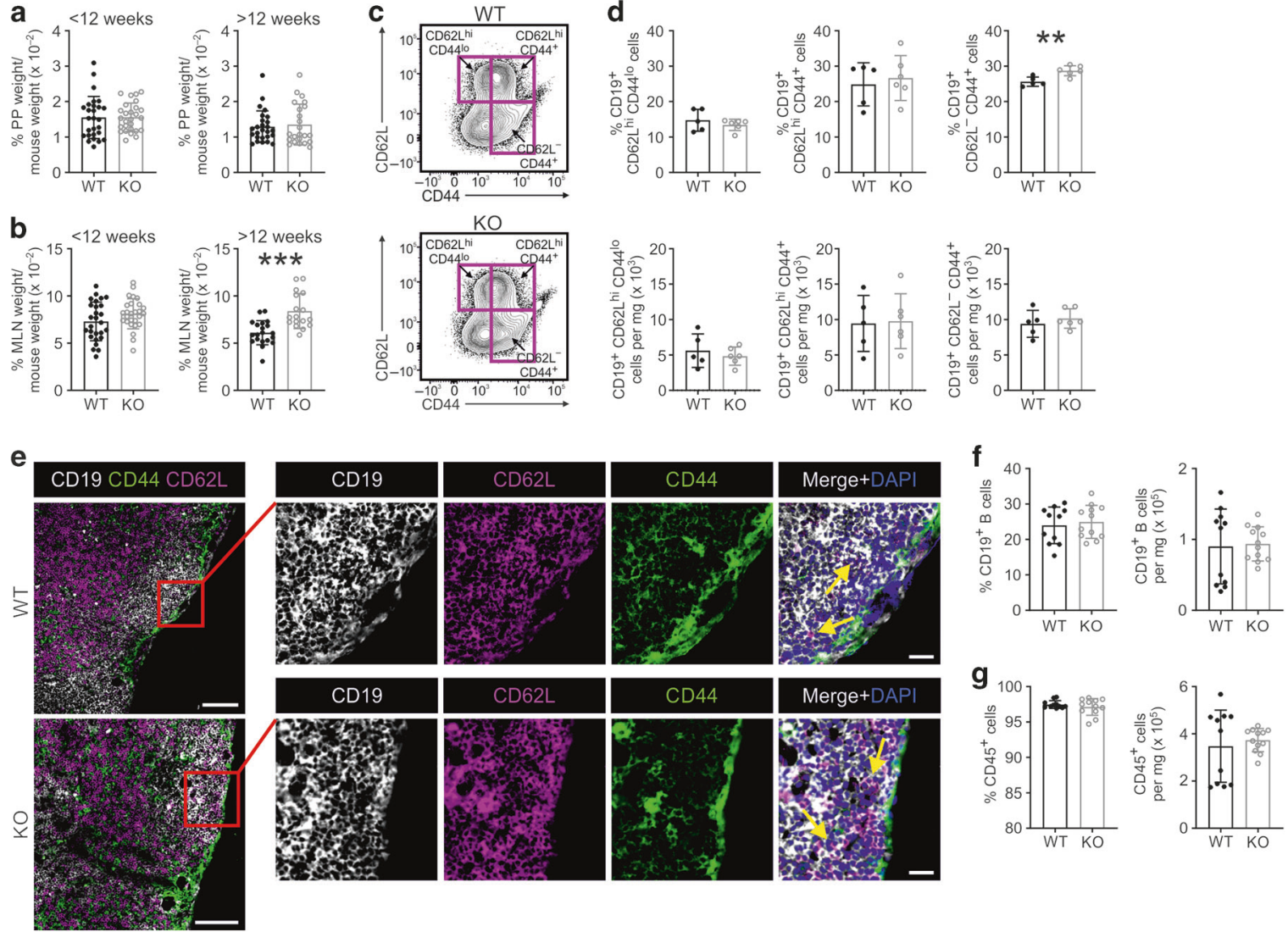
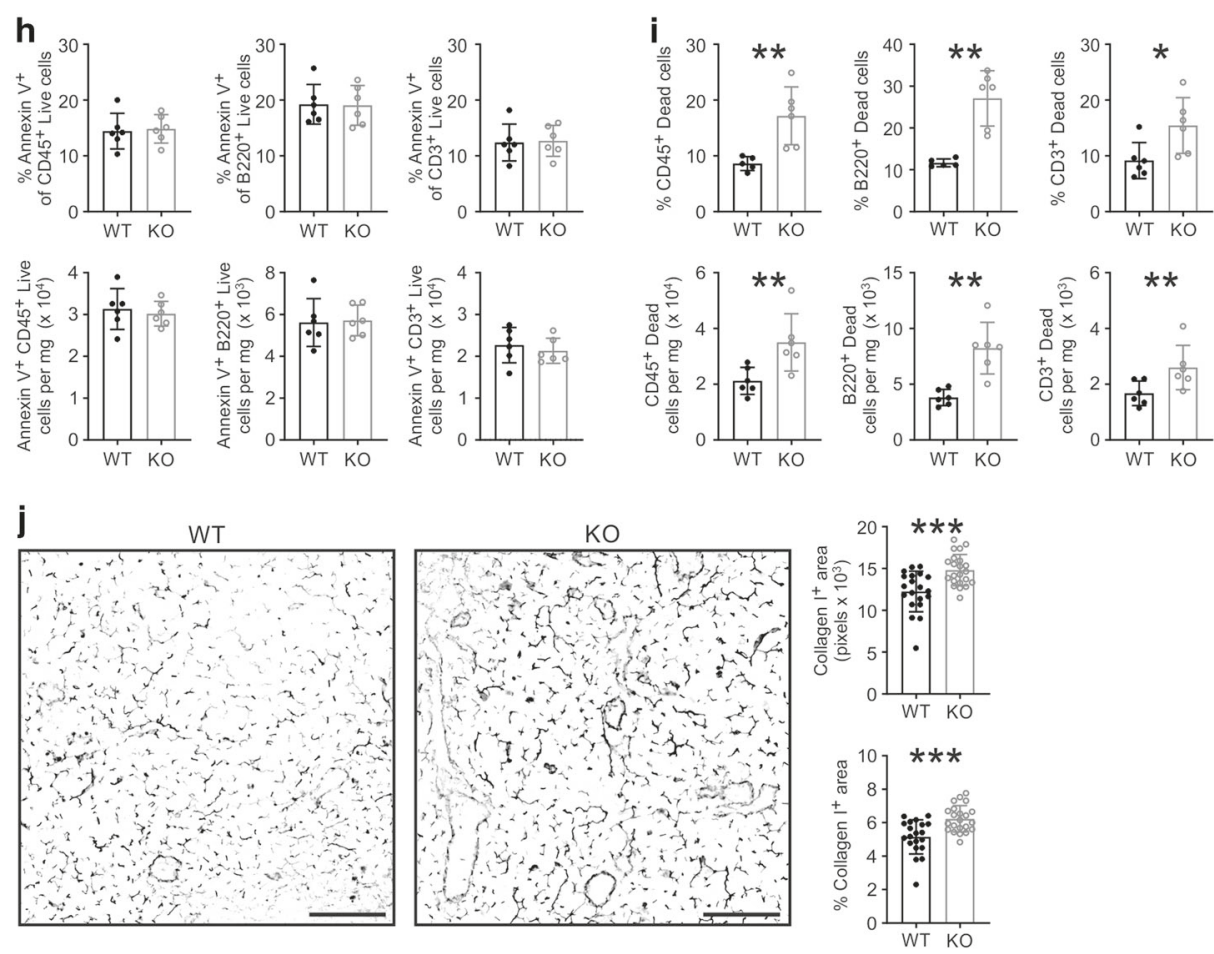

BEC were isolated as described previously. ${ }^{12}$ Cells were blocked using the anti-CD16/CD32 Mouse BD Fc Block ${ }^{\mathrm{TM}}$ (BD 553141) or $5 \%$ rat serum before staining the cells with appropriate combinations of fluorescently labeled monoclonal antibodies. Cells were analyzed with an LSR II or LSR Fortessa cytometer (Becton Dickinson) that were appropriately calibrated for each antibody cocktail using UltraComp eBeads ${ }^{\mathrm{TM}}$ Compensation beads (Invitrogen ${ }^{\mathrm{TM}}$, 01-2222-41). Data was analyzed using FlowJo software (FlowJo LLC). 
Fig. 7 Differences in cell death and collagen homeostasis lead to increased MLN size in Robo4 KO mice. a, b Weight of single PP a and MLN b in relation to the total weight of the mouse analyzed from Robo4 KO and WT mice under the age of 12 weeks or 12 weeks and older. Tissues were weighed from 27 WT and 27 KO (<12 weeks), 20-26 WT and 17-23 KO (>12 weeks) mice. c, d Gating and analysis of CD19 ${ }^{+}$B cell subpopulations from $>12$ weeks old mice. c FACS plots of $\mathrm{CD} 19^{+}$subpopulations from Robo4 KO and WT MLN analyzed from $>12$-week-old mice. d Frequency (\%) and total cell numbers in relation to mg of tissue for CD19 ${ }^{+} \mathrm{CD}_{22} \mathrm{~L}^{\mathrm{hi}} \mathrm{CD} 44^{\mathrm{lo}}$ (left), $\mathrm{CD} 19^{+} \mathrm{CD} 62 \mathrm{~L}^{\mathrm{hi}} \mathrm{CD} 44^{+}$(middle) and $\mathrm{CD} 19^{+} \mathrm{CD} 62 \mathrm{~L}^{-} \mathrm{CD} 44^{+}$(right) B cells recovered by flow cytometry of MLN of Robo4 KO and WT mice, age $>12$ weeks. Data are representative of two independent experiments performed with a total of 11-12 WT and KO mice. e Localization of CD19+CD62L ${ }^{\text {hi }} \mathrm{CD} 44^{\mathrm{lo}} \mathrm{B}$ cells in MLN of Robo4 KO and WT detected by immunostaining, age $>12$ weeks. Arrows point to these cells (scale bars $100 \mu \mathrm{m}$ in main images, $20 \mu \mathrm{m}$ in zoom-ins). $\mathbf{f}$, $\mathbf{g}$ Frequency (\%) and total cell numbers in relation to $\mathrm{mg}$ of tissue of $\mathrm{CD} 19^{+}$B cells $\mathbf{f}$ and CD45 $5^{+}$cells $\mathbf{g}$ analyzed by flow cytometry from Robo4 KO and WT MLN, age > 12 weeks. Data are pooled from two independent experiments with 11 WT and 12 KO mice. $\mathbf{h}$, i Frequency (\%) and total cell numbers in relation to $\mathrm{mg}$ of tissue of early apoptotic Annexin ${ }^{+} \mathrm{CD}^{+} 5^{+}$cells, Annexin ${ }^{+} \mathrm{B} 22 \mathrm{O}^{+} \mathrm{B}$ cells, and Annexin ${ }^{+} \mathrm{CD}^{+} \mathrm{T}$ cells $\mathbf{h}$, as well as dead $\mathrm{CD} 45^{+}$, dead $\mathrm{B}_{2} 20^{+}$, and dead $\mathrm{CD} 3^{+}$cells $\mathbf{i}$ analyzed from Robo4 KO and WT MLN, age $>12$ weeks. 5-6 WT and 6 KO mice were analyzed. $\mathbf{j}$ Quantification of collagen I from fluorescence images of Robo4 KO and WT MLNs, age $>12$ weeks. Examples of the collagen I expression (left), combined results of the expression (right). Images were acquired from six WT and six KO mice and collagen I was quantified from two regions of $0.24 \mathrm{~mm}^{2}$ for each MLN, scale bars $100 \mu \mathrm{m}$. Each dot represents an individual mouse (a, $\mathbf{b}$, $\left.\mathbf{d}, \mathbf{f}-\mathbf{i}\right)$ or an analyzed sample j. Data are presented as mean \pm S.D. ${ }^{*} P<0.05,{ }^{* *} P<0.01,{ }^{* *} P<0.001$ (Mann-Whitney U-test).

\section{Subcutaneous administration of anti-Robo4 antibody} In-house produced monoclonal anti-Robo4 antibody (see Supplementary methods) was conjugated using the Alexa Fluor ${ }^{\mathrm{TM}} 647$ Protein Labeling Kit (Invitrogen ${ }^{\mathrm{TM}}$, A20173). Before injections, the antibody was filtered using a $10-\mathrm{kDa}$ cut-off centrifugal filter unit (Millipore, MRCPRT010) to remove any free fluorochromes. A blocking mixture targeted to block the Fc receptors present on macrophages was a combination of $50 \mu \mathrm{g}$ anti-CD16/CD32 (clone 2.4G2, Bio $X$ Cell BE0307) and $50 \mu \mathrm{g}$ mouse immunoglobulins (Rockland 010-0102-0005). $20 \mu \mathrm{l}$ of the blocking mixture was administered to the footpads of C57BL/6 mice, which were under light isoflurane anesthesia. The blocking antibodies and immunoglobulins were let to drain to the popliteal lymph node for $15 \mathrm{~min} .5 \mu \mathrm{g}$ of anti-Robo4 antibody (clone FuRFM7) was injected simultaneously with $50 \mu \mathrm{g}$ of anti-CD16/CD32 and $50 \mu \mathrm{g}$ of mouse Ig s.c. to the calves of the mice and antibodies were let to drain to the popliteal lymph node for an additional $15 \mathrm{~min}$ after which the mice were sacrificed, the lymph nodes excised, embedded in optimal cutting temperature (OCT) medium in a predetermined orientation in order to produce transverse sections of the lymph node and snap-frozen using dry ice. The samples were stored at $-70^{\circ} \mathrm{C}$ and $6 \mu \mathrm{m}$ sections were cut for imaging. The lymph node tissue sections were subjected to immunofluorescence staining of vascular and lymphatic markers CD31-A488 (BioLegend ${ }^{\oplus}, 102514$ ) and LYVE1 (ReliaTech $\left.\mathrm{GmbH}, 103-P A 50\right)$ followed by a conjugated secondary antibody, Goat anti-rabbit Alexa Fluor ${ }^{\oplus}$ 546 (Invitrogen ${ }^{\mathrm{TM}}, \mathrm{A} 11035$ ). Samples were imaged using a LSM780 confocal microscope (Carl Zeiss) as described below.

\section{Immunohistochemistry}

Processing tissues for microscopy. Harvesting and treating PP for imaging was performed as previously described. ${ }^{34}$ Upon harvesting PP no external pressure was applied to the tissue in order to preserve the lymphatic contents. PP were harvested attached to a ring of the intestine that was flushed with PBS to empty the intestinal contents. The PP were fixed in 4\% PFA for 2-4 h, washed twice with PBS and incubated overnight in $30 \%$ sucrose. On the following day, PP were embedded in OCT medium in a predetermined position in order to produce transverse sections of the PP. Inguinal lymph nodes and the MLN were harvested and excess fat tissue was removed. LN were fixed in 4\% PFA for $2-4 \mathrm{~h}$, incubated in $30 \%$ sucrose overnight and embedded in OCT medium on the following day. Blocks were snap-frozen using dry ice, stored at $-70^{\circ} \mathrm{C}$ and used for cutting $6 \mu \mathrm{m}$ sections. Tissue sections were subjected for immunofluorescence staining by incubating them with predetermined antibody dilutions for 30-60 min each at room temperature. Stained sections were mounted using ProLong ${ }^{\mathrm{TM}}$ Gold Antifade Mountant with DAPI (Invitrogen ${ }^{\mathrm{TM}}$, P36931) or without DAPI (Invitrogen ${ }^{\text {TM }}$, P10144). In some cases, PP and MLN were embedded in OCT medium without PFA fixation and the sections were subsequently fixed with ice-cold acetone before staining.

Human lymph nodes and appendixes were collected from three different donors and they were embedded in OCT medium, snapfrozen with dry ice, stored at $-70^{\circ} \mathrm{C}$ and used for cutting $5 \mu \mathrm{m}$ sections fixed with acetone. Non-specific-binding sites were blocked with $5 \%$ human $A B$ serum for $10 \mathrm{~min}$ at room temperature. Sections were stained with predetermined antibody dilutions for $30 \mathrm{~min}$ each at room temperature and mounted using ProLong $^{\text {TM }}$ Gold Antifade Mountant.

Imaging. The immunofluorescently stained sections were imaged using a LSM780 or LSM880 confocal microscope (Carl Zeiss) with a Plan-Apochromat $\times 20 / 0.8$ objective. Zen 2010 or Zen 2.3 SP1 FP2 software (Carl Zeiss) was used for acquiring images. The same slice thickness for each channel was determined by adjusting the pinhole resulting in a slice thickness varying from 2.3 to $8.8 \mu \mathrm{m}$. In some cases, images were acquired using an Olympus BX60 fluorescence microscope (Tokyo, Japan) equipped with a UPlanFI $\times 20 / 0.50$ or an UPlanFI $\times 40 / 0.75$ objective or a Nikon Eclipse TI-E fluorescence microscope and a Plan Apo lamda $\times 20$ / 0.80 objective.

Image analyses were performed using ImageJ software (version 1.52i). Linear brightness adjustments were applied equally to Robo4 KO and WT images, as well as human tissue images and their controls. Image quantification was performed by thresholding the appropriate signal and calculating area fractions for the tissues. Thresholding was applied equally to all analyzed images. When analyzing collagen I, background subtraction was performed before thresholding. Adoptive transfer image quantifications were done by thresholding CD45.1 $1^{+}$signal and calculating area fractions of determined regions of interest, such as follicular and interfollicular regions (PP) or $\mathrm{CD}_{19}{ }^{+} \mathrm{B}$ cell regions, as well as $\mathrm{CD}^{+}{ }^{+}$T cell regions (MLN, PLN). MLN samples were analyzed from a representative area of $1.61-1.62 \mathrm{~mm}^{2}$. Collagen $\mathrm{I}^{+}$signal was thresholded and the total area and percentage of collagen $\mathrm{I}^{+}$ signal were analyzed from two representative $0.24 \mathrm{~mm}^{2}$ areas/ sample.

\section{Apoptosis assay}

Annexin V. To analyze the apoptotic rate and dead cells in Robo4 KO and WT tissues, we stained single-cell suspensions extracted from PP and MLN with Fixable Viability Dye efluor 506 (eBioscience 65-0866-14) diluted in PBS for 30 min on ice. After washes, the cells were blocked with the anti-CD16/CD32 Mouse $\mathrm{BD}$ Fc Block ${ }^{\mathrm{TM}}$ and incubated with fluorescently conjugated antibodies for $30 \mathrm{~min}$ on ice as described above. After staining with antibodies, cells were washed with PBS and incubated with Annexin V-PE (BD 556422) diluted 1:200 in 1x Annexin-staining buffer comprised of $0.01 \mathrm{M}$ HEPES $(\mathrm{pH} 7.4), 0.14 \mathrm{M} \mathrm{NaCl}$, and 
$2.5 \mathrm{mM} \mathrm{CaCl}$. The samples were incubated for $15 \mathrm{~min}$ at room temperature, additional Annexin-staining buffer was added to the cells and samples were analyzed immediately using an LSR Fortessa cytometer (Becton Dickinson).

TUNEL. Robo4 KO and WT PP were harvested, fixed in 4\% PFA for $4 \mathrm{~h}$, washed with PBS twice and incubated overnight in $30 \%$ sucrose. PP were mounted the following day in OCT medium as described above. Frozen sections of $5-6 \mu \mathrm{m}$ were cut and apoptotic cells were detected from Robo4 KO and WT PP using the commercially available Click-iT ${ }^{\mathrm{TM}}$ Plus TUNEL Assay (Invitrogen $^{\mathrm{TM}}$, C10618) fluorescently detecting the $3^{\prime}-\mathrm{OH}$ ends of fragmented DNA. The assay was performed according to the manufacturer's instructions. The sections were subsequently subjected to antibody staining detecting $B$ cells and lymphatics. TUNEL staining was quantified using ImageJ by thresholding the $\mathrm{TUNEL}^{+}$signal and calculating area fractions of the signal in relation to the whole PP or follicular areas.

Intravenous staining of PP HEV

Mucosal HEV were quantified using intravenous labeling of endothelial cells with anti-MAdCAM-1 antibody. For quantifying MAdCAM- $1^{+}$HEVs in Robo4 KO and WT PP tissue sections, $10 \mu \mathrm{g}$ of anti-MAdCAM-1 antibody (clone Meca367, a gift from Prof. E. Butcher) was administered to Robo4 KO and WT mice intravenously to label the lumens of HEVs. Mice were sacrificed 10 min later and the PP were harvested. Frozen sections were stained with the secondary antibody Goat anti-rat lgG Alexa Fluor 546 (Invitrogen $^{\mathrm{TM}}, \mathrm{A} 11081$ ) detecting Meca367. The sections were simultaneously stained for CD31 and lgD.

\section{Adoptive transfer assays}

Lymphocytes were isolated from skin-draining, mesenteric and cervical lymph nodes of wild-type, congenic CD45.1 $1^{+}$donor mice. Tissues were homogenized using metal custom-made cell strainers to produce a single-cell suspension. $12 \times 10^{6} \mathrm{CD} 45.1^{+}$ lymphocytes were intravenously transferred into CD45.2 $2^{+}$Robo4 KO and WT mice. PLN (inguinal, axillary, brachial), MLN, PP, and peripheral blood of the recipient mice were analyzed 2 and $18 \mathrm{~h}$ after the intravenous transfer.

In another set of experiments, lymphocytes were isolated from the spleens, skin-draining lymph nodes, and cervical lymph nodes of Robo4 WT mice. Donor cells were labeled with $0.5 \mu \mathrm{M}$ CellTrace $^{\mathrm{TM}}$ CFSE (Invitrogen ${ }^{\mathrm{TM}}, \mathrm{C}$ C34554) and $10 \times 10^{6}$ cells were subcutaneously injected into the hind leg footpads of Robo4 KO and WT recipient mice. Popliteal and iliac lymph nodes were analyzed with flow cytometry $12 \mathrm{~h}$ after the adoptive transfer.

FITC injection into PP

FITC injection into PP was done as previously described. ${ }^{38}$ Briefly, mice were anesthetized and the small intestine was exposed after small incisions into the skin and peritoneum. Fluorescein isothiocyanate (FITC, Sigma-Aldrich) solution diluted in PBS at the concentration of $1 \mathrm{mg} / \mathrm{ml}$ was injected into 4-5 PP per mouse. For injections, fine glass capillaries connected to a microinjector (Harvard Apparatus) were used. After the injections, the small intestine was placed back into the abdominal cavity and the wounds were closed with sutures and metal clips. The mice were analyzed 1 day after the FITC injections with flow cytometry.

\section{Ex vivo-adhesion assays}

In principle, the adhesion assays were performed as described earlier. ${ }^{23}$ Briefly, human lymphocytes from healthy volunteers were isolated from peripheral blood using Ficoll-Paque ${ }^{\mathrm{TM}}$ (GE Healthcare) density gradient purification. Isolated lymphocytes were incubated on freshly cut frozen sections of human peripheral lymph nodes pre-treated for 30 min with rabbit anti-human Robo4 antibody (ab10547, Abcam) or normal rabbit serum as a negative control. Lymphocytes were allowed to bind to the sinuses for 5 min in rotatory conditions, in steady-state conditions for $15 \mathrm{~min}$ followed by $5 \mathrm{~min}$ in rotatory conditions and thereafter, $15 \mathrm{~min}$ without rotation at $+7{ }^{\circ} \mathrm{C}$. The non-bound cells were gently decanted off from the sections and adherent cells were fixed with $1 \%$ glutaraldehyde. The number of lymphocytes bound to the SS and LS was counted under dark-field microscopy. To be able to standardize day-to-day variations between the experiments, the binding of lymphocytes to the control sections was set to $100 \%$ by definition.

\section{Statistical analyses}

Sample size for experiments was determined with pilot assays. All numerical data are presented as mean \pm S.D. Comparisons between the genotypes or differently treated groups were analyzed using the Mann-Whitney $U$-test or the two-tailed Student's $t$-test. All statistical analyses were performed with GraphPad Prism v7 software (GraphPad software Inc.). Outliers in data were determined using the Grubb's test available from GraphPad Prism and removed from the analyses. $P$-values under 0.05 were considered as statistically significant.

\section{ACKNOWLEDGEMENTS}

We thank Heidi Gerke, Riikka Sjöroos, Riina Mankonen, Sari Mäki, and Etta-Liisa Väänänen for technical help, as well as Marko Salmi for the supervision and financial support of H.-M.B. We acknowledge the Cell Imaging Core at the Turku Centre for Biotechnology. This work was supported by the Finnish Academy, the Finnish Cancer Foundation, the Sigrid Juselius Foundation, and a grant by the Deutsche Forschungsgemeinschaft DFG PA921/3-1. This work benefited from data assembled by the ImmGen consortium.

\section{AUTHOR CONTRIBUTIONS}

S.J., R.F.-M., M.M., and O.P. designed the experiments. R.F.-M., M.U., I.I.-E-K., L.K., A.K.-M., and H.-M.B. performed and analyzed the experiments. K.E. collected the data. R.F.-M. and S.J. wrote the first drafts and all authors contributed to the final version of the manuscript.

\section{ADDITIONAL INFORMATION}

The online version of this article (https://doi.org/10.1038/s41385-019-0230-9) contains supplementary material, which is available to authorized users.

Competing interests: The authors declare no competing interests.

Publisher's note Springer Nature remains neutral with regard to jurisdictional claims in published maps and institutional affiliations.

\section{REFERENCES}

1. Gowans, J. L. \& Knight, E. J. The route of re-circulation of lymphocytes in rat. Proc R. Soc. Lond. B 159, 257-282 (1964)

2. Habtezion, A., Nguyen, L. P., Hadeiba, H. \& Butcher, E. C. Leukocyte trafficking to the small intestine and colon. Gastroenterology 150, 340-354 (2016).

3. Miyasaka, M. \& Tanaka, T. Lymphocyte trafficking across high endothelial venules: dogmas and enigmas. Nat. Rev. Immunol. 4, 360-370 (2004).

4. Bevilacqua, M. et al. Selectins: a family of adhesion receptors. Cell 67, 233 (1991).

5. McEver, R. P. Selectins: initiators of leucocyte adhesion and signalling at the vascular wall. Cardiovasc. Res. 107, 331-339 (2015).

6. Teijeira, A., Rouzaut, A. \& Melero, I. Initial afferent lymphatic vessels controlling outbound leukocyte traffic from skin to lymph nodes. Front. Immunol. 4, 433 (2013).

7. Hunter, M. C., Teijeira, A. \& Halin, C. T. Cell trafficking through lymphatic vessels. Front. Immunol. 7, 613 (2016).

8. Randolph, G. J., Ivanov, S., Zinselmeyer, B. H. \& Scallan, J. P. The lymphatic system: integral roles in immunity. Annu. Rev. Immunol. 35, 31-52 (2017).

9. Forster, R., Braun, A. \& Worbs, T. Lymph node homing of T cells and dendritic cells via afferent lymphatics. Trends Immunol. 33, 271-280 (2012).

10. Kawashima, Y., Sugimura, M., Hwang, Y.-C. \& Kudo, N. The lymph system in mice. Jpn. J. Vet. Res. 12, 69-78 (1964). 
11. Guy-Grand, D., Griscelli, C. \& Vassalli, P. The gut-associated lymphoid system: nature and properties of the large dividing cells. Eur. J. Immunol. 4, 435-443 (1974).

12. Iftakhar, E. K. I. et al. Gene-expression profiling of different arms of lymphatic vasculature identifies candidates for manipulation of cell traffic. Proc. Natl Acad. Sci. USA 113, 10643-10648 (2016).

13. Huminiecki, L., Gorn, M., Suchting, S., Poulsom, R. \& Bicknell, R. Magic roundabout is a new member of the roundabout receptor family that is endothelial specific and expressed at sites of active angiogenesis. Genomics 79, 547-552 (2002).

14. Smith-Berdan, S. et al. Robo4 cooperates with CXCR4 to specify hematopoietic stem cell localization to bone marrow niches. Cell Stem Cell 8, 72-83 (2011).

15. Smith-Berdan, S., Nguyen, A., Hong, M. A. \& Forsberg, E. C. ROBO4-mediated vascular integrity regulates the directionality of hematopoietic stem cell trafficking. Stem Cell Rep. 4, 255-268 (2015).

16. Jones, C. A. et al. Robo4 stabilizes the vascular network by inhibiting pathologic angiogenesis and endothelial hyperpermeability. Nat. Med. 14, 448-453 (2008).

17. Koch, A. W. et al. Robo4 maintains vessel integrity and inhibits angiogenesis by interacting with UNC5B. Dev. Cell 20, 33-46 (2011).

18. Park, K. W. et al. Robo4 is a vascular-specific receptor that inhibits endothelial migration. Dev. Biol. 261, 251-267 (2003).

19. Zhang, B. et al. Repulsive axon guidance molecule Slit3 is a novel angiogenic factor. Blood 114, 4300-4309 (2009).

20. Zhao, H., Anand, A. R. \& Ganju, R. K. Slit2-Robo4 pathway modulates lipopolysaccharide-induced endothelial inflammation and its expression is dysregulated during endotoxemia. J. Immunol. 192, 385-393 (2014).

21. $\mathrm{Yu}$, J. et al. Slit2N and Robo4 regulate lymphangiogenesis through the VEGF-C/ VEGFR-3 pathway. Cell Commun. Signal. 12, 25 (2014).

22. Kähäri, L. et al. Transcytosis route mediates rapid delivery of intact antibodies to draining lymph nodes. J. Clin. Invest. 129, 3086-3102 (2019).

23. Irjala, H. et al. Mannose receptor is a novel ligand for L-selectin and mediates lymphocyte binding to lymphatic endothelium. J. Exp. Med. 194, 1033-1042 (2001).

24. Marlow, R. et al. Vascular Robo4 restricts proangiogenic VEGF signaling in breast. Proc. Natl Acad. Sci. USA 107, 10520-10525 (2010).

25. Salmi, M. \& Jalkanen, S. How do lymphocytes know where to go: current concepts and enigmas of lymphocyte homing. Adv. Immunol. 64, 139-218 (1997).
26. Stamper, H. B. Jr. \& Woodruff, J. J. Lymphocyte homing into lymph nodes: in vitro demonstration of the selective affinity of recirculating lymphocytes for highendothelial venules. J. Exp. Med. 144, 828-833 (1976).

27. Jalkanen, S., Bargatze, R., Herron, L. \& Butcher, E. C. Human lymphocyte-high endothelial venule interaction: functional and molecular characterization. Adv. Exp. Med. Biol. 186, 615-620 (1985).

28. Irjala, H. et al. Mannose receptor (MR) and common lymphatic endothelial and vascular endothelial receptor (CLEVER)- 1 direct the binding of cancer cells to the lymph vessel endothelium. Cancer Res. 63, 4671-4676 (2003).

29. Pals, S. T. et al. Evidence that leukocyte-function associated antigen-1 is involved in recirculation and homing of lymphocytes via high endothelial venules. J. Immunol. 140, 1851-1853 (1988).

30. Streeter, P. R., Rouse, B. T. N. \& Butcher, E. C. Immunohistologic and functional characterization of a vascular addressin involved in lymphocyte homing into peripheral lymph nodes. J. Cell Biol. 107, 1853-1862 (1988).

31. Yednock, T. A. et al. Prevention of experimental autoimmune encephalomyelitis by antibodies against a4b1 integrin. Nature 356, 63-66 (1992).

32. Salmi, M. \& Jalkanen, S. A 90-kilodalton endothelial cell molecule mediating lymphocyte binding in humans. Science 257, 1407-1409 (1992).

33. Irjala, $\mathrm{H}$. et al. The same endothelial receptor controls lymphocyte traffic both in vascular and lymphatic vessels. Eur. J. Immunol. 33, 815-824 (2003).

34. Schmidt, T. H., Bannard, O., Gray, E. E. \& Cyster, J. G. CXCR4 promotes B cell egress from Peyer's patches. J. Exp. Med. 210, 1099-1107 (2013).

35. Gohda, M. et al. Sphingosine 1-phosphate regulates the egress of IgA plasmablasts from Peyer's patches for intestinal IgA responses. J. Immunol. 180, 5335-5343 (2008)

36. Geherin, S. A., Wilson, R. P., Jennrich, S. \& Debes, G. F. CXCR4 is dispensable for T cell egress from chronically inflamed skin via the afferent lymph. PLOS ONE 9, e95626 (2014)

37. Tang, T. et al. A mouse knockout library for secreted and transmembrane proteins. Nat. Biotechnol. 28, 749-755 (2010).

38. Schulz, O. et al. Hypertrophy of infected Peyer's patches arises from global, interferon-receptor, and CD69-independent shutdown of lymphocyte egress. Mucosal Immunol. 7, 892-904 (2014). 